\title{
Phytosterols: From Preclinical Evidence to Potential Clinical Applications
}

\author{
Bahare Salehi ${ }^{1}$, Cristina Quispe ${ }^{2}$, Javad Sharifi-Rad ${ }^{3,4 *}$, Natália Cruz-Martins ${ }^{5,6,7}$, \\ Manisha Nigam ${ }^{8}$, Abhay Prakash Mishra ${ }^{9}$, Dmitryi Alexeevich Konovalov ${ }^{10}$, \\ Valeriya Orobinskaya ${ }^{11}$, Ibrahim M. Abu-Reidah ${ }^{12}$, Wissam Zam ${ }^{13 *}$, Farukh Sharopov ${ }^{14 *}$, \\ Tommaso Venneri ${ }^{15}$, Raffaele Capasso ${ }^{16}$, Wirginia Kukula-Koch ${ }^{17}$, Anna Wawruszak ${ }^{18}$ and \\ Wojciech Koch ${ }^{19 *}$
}

\section{OPEN ACCESS}

Edited by:

Marcello Locatelli,

University of Studies G. d'Annunzio

Chieti and Pescara, Italy

Reviewed by:

Antonio Cilla,

University of Valencia, Spain

Magdalena Rudzińska,

Poznan University of Life Sciences,

Poland

*Correspondence:

Javad Sharifi-Rad

javad.sharifirad@gmail.com

Wissam Zam

ws.sarah2005@gmail.com

Farukh Sharopov shfarukh@mail.ru

Wojciech Koch

kochw@interia.p

Specialty section:

This article was submitted to

Ethnopharmacology,

a section of the journal

Frontiers in Pharmacology

Received: 28 August 2020

Accepted: 14 October 2020

Published: 14 January 2021

Citation:

Salehi B, Quispe C, Sharifi-Rad J, Cruz-Martins N, Nigam M, Mishra AP

Konovalov DA, Orobinskaya $V$, Abu-Reidah IM, Zam W, Sharopov F,

Venneri T, Capasso $R$,

Kukula-Koch W, Wawruszak A and Koch W (2021) Phytosterols: From

Preclinical Evidence to Potential

Clinical Applications.

Front. Pharmacol. 11:599959.

doi: 10.3389/fphar.2020.599959
${ }^{1}$ Medical Ethics and Law Research Center, Shahid Beheshti University of Medical Sciences, Tehran, Iran, ${ }^{2}$ Facultad de Ciencias de la Salud, Universidad Arturo Prat, Iquique, Chile, ${ }^{3}$ Phytochemistry Research Center, Shahid Beheshti University of Medical Sciences, Tehran, Iran, ${ }^{4}$ Facultad de Medicina, Universidad del Azuay, Cuenca, Ecuador, ${ }^{5}$ Faculty of Medicine, University of Porto, Porto, Portugal, ${ }^{6}$ Institute for Research and Innovation in Health (i3S), University of Porto, Porto, Portugal, ${ }^{7}$ Laboratory of Neuropsychophysiology, Faculty of Psychology and Education Sciences, University of Porto, Porto, Portugal, ${ }^{8}$ Department of Biochemistry, H. N. B. Garhwal (A Central) University, Srinagar Garhwal, India, ${ }^{9}$ Adarsh Vijendra Institute of Pharmaceutical Sciences, School of Pharmacy, Shobhit University, Gangoh, India, ${ }^{10}$ Department of Pharmacognosy, Botany and Technology of Phytopreparations, Pyatigorsk Medical-Pharmaceutical Institute, Branch of Volgograd State Medical University, Ministry of Health of Russia, Pyatigorsk, Russia, ${ }^{11}$ Institute of Service, Tourism and Design (Branch) of North-Caucasus Federal University in Pyatigorsk, Pyatigorsk, Russia, ${ }^{12}$ Department of Environmental Science/Boreal Ecosystem Research Initiative, Memorial University of Newfoundland, Corner Brook, NL, Canada, ${ }^{13}$ Department of Analytical and Food Chemistry, Faculty of Pharmacy, Al-Andalus University for Medical Sciences, Tartous, Syria, ${ }^{14}$ "Chinese-Tajik Innovation Center for Natural Products", Academy of Sciences of the Republic of Tajikistan, Dushanbe, Tajikistan, ${ }^{15}$ Department of Pharmacy, University of Napoli Federico II, Napoli, Italy, ${ }^{16}$ Department of Agricultural Sciences, University of Naples Federico II, Portici, Italy, ${ }^{17}$ Department of Pharmacognosy, Medical University of Lublin, Lublin, Poland, ${ }^{18}$ Department of Biochemistry and Molecular Biology, Medical University of Lublin, Lublin, Poland, ${ }^{19}$ Chair and Department of Food and Nutrition, Medical University of Lublin, Lublin, Poland

Phytosterols (PSs) are plant-originated steroids. Over 250 PSs have been isolated, and each plant species contains a characteristic phytosterol composition. A wide number of studies have reported remarkable pharmacological effects of PSs, acting as chemopreventive, anti-inflammatory, antioxidant, antidiabetic, and antiatherosclerotic agents. However, PS bioavailability is a key issue, as it can be influenced by several factors (type, source, processing, preparation, delivery method, food matrix, dose, time of administration into the body, and genetic factors), and the existence of a close relationship between their chemical structures (e.g., saturation degree and side-chain length) and low absorption rates has been stated. In this sense, the present review intends to provide indepth data on PS therapeutic potential for human health, also emphasizing their preclinical effects and bioavailability-related issues.

Keywords: phytosterols, $\beta$-sitosterol, campesterol, low-density lipoprotein cholesterol, coronary heart disease

\section{INTRODUCTION}

Consumer awareness for healthy lifestyles, seeking optimal health and longevity, has moved primary attention toward nutrition that offers health potentialities beyond staple food. In fact, bioactive-rich diets at appropriate amounts are invaluable for health maintenance (Floros et al., 2010), where the impact of a balanced diet is crucial. Often conceived as providing a proper variety of distinct types of food and concomitantly adequate amounts of the required nutrients to ensure good health and 


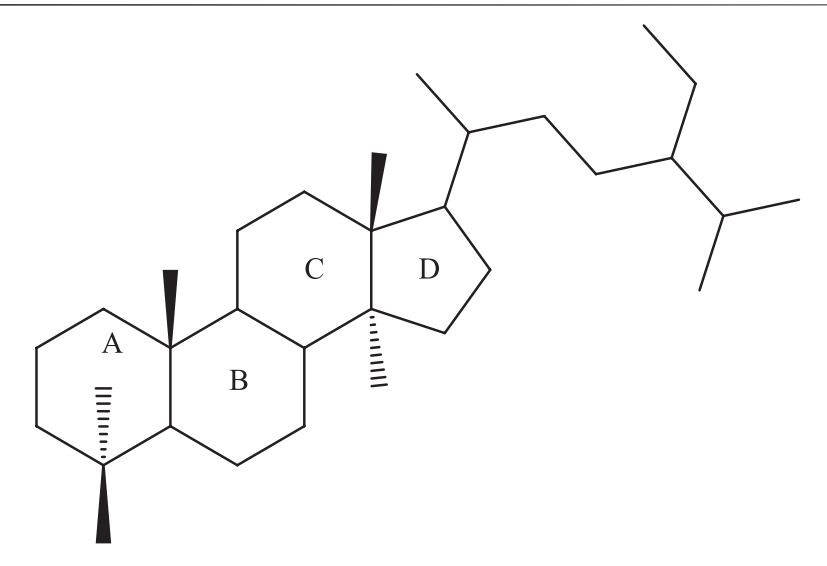

FIGURE 1 | The steroid skeleton.

maintain health vitality, welfare, and proper body function (Shao et al., 2017), a balanced diet has been increasingly adopted by consumers worldwide. There is a wide variety of plant-derived bioactive molecules that have been increasingly consumed by human beings given their renowned health benefits (Salehi et al., 2018; Sharifi-Rad et al., 2018; Imran et al., 2019). These molecules, often called phytochemicals, include phenolic compounds, organic acids, carotenoids, alkaloids, and sterols. Broadly, plant sterols are functional ingredients solely obtained from plant resources (Piironen et al., 2003).

Phytosterols (PSs) are plant-derived fatty compounds (steroids) representing the greatest portion of unsaponifiable matter in plant lipids (Piironen et al., 2003), while cholesterol is present in animals. They consist of a steroid skeleton characterized by a saturated bond between C- 5 and C- 6 of the sterol moiety. They have an aliphatic side chain attached to the $\mathrm{C}$ 17 atom and a hydroxyl group attached to the C-3 atom (Figure 1). Cholesterol and plant sterols are originally found as nonesterified and esterified forms of cinnamic acid/fatty acids (FA) or as glycosides. The bound form is usually hydrolyzed in the small intestine by pancreatic enzymes. Free dietary cholesterol absorption in human gut has been estimated at up to $50 \%$, depending on variations of PS structure and molecular weight (Fassbender et al., 2008).

All plant species have its characteristic PS composition (Ogbe et al., 2015), with more than 250 PS being recognized so far. Although PS are found in all plant foods, unrefined plant oils, including vegetable, nuts and olive oils, such as sesame, safflower, soybeans, peas, macadamia, and almonds are extremely rich sources; however, nuts, seeds, whole grains, and legumes are also good dietary sources of PS (Sharifi-Rad et al., 2018; Piironen et al., 2003; (Wadikar et al., 2017). They are classified into sterols and stanols, representing the unsaturated and saturated molecules, respectively (Piironen et al., 2000). Beta-sitosterol, 4 of 47 campesterol, and stigmasterol (Figure 2) are the most common plant-derived sterols in human diet. All contain a core skeleton of cholesterol but possess a different side chain. Betasitosterol and stigmasterol have an ethyl group at C-24, whereas campesterol is equipped with a C24-methyl group. Stigmasterol derives from sitosterol by the action of sterol C-22 desaturases. Brassicasterol, and D-7-avenasterol are minor constituents. Stanols are also found in plants, although they form only $10 \%$ of total dietary phytosterol (PS) (Jones and AbuMweis, 2009).

Briefly, PSs are biologically active molecules with multiple health applications, and increasing evidence has shown that PS activity depends on various criteria, such as formulation and solubility in the food matrix (Schiepers et al., 2009; Poudel et al., 2019). Nonetheless, as humans cannot synthetize PSs, they should obtain them from diet (Cabral and Klein, 2017).

There is increasing scientific evidence supporting the idea that PSs and their derivatives have multiple pharmacological properties, including human-wellness-promoting abilities. These health benefits include a great ability to reduce total and low-density lipoprotein (LDL) cholesterol levels, thus decreasing the risk of many diseases (Plat et al., 2019). Moreover, PSs also modulate inflammation; have antioxidant, antiulcer, immunomodulatory, antibacterial, and antifungal effects; and also intervene in wound healing promotion and platelet aggregation inhibition (Dutta, 2003; Ogbe et al., 2015).

To what concerns to PS health effects and given its long history of safe consumption, they have been targeted of an increasingly specific and highly regulated labeling to ensure consumers protection and safety. So far, the authorized health claims for PS consumption, when consumed as part of a healthy diet and lifestyle, are directly related to its ability to help maintain or reduce the low-density lipoprotein cholesterol (LDL-C) level, with marked reductions in blood cholesterol of $7-12.5 \%$ for intakes of $1.5-3 \mathrm{~g} /$ day (Shortt, 2015). In addition, issues related to plant sterols and stanols safety have already been declared by international agencies, such as the Food and Drug Administration (FDA) and the European Union Scientific Committee (EUSC) (Dutta, 2003), which clearly reveals their promissory potential at the same time that denotes the huge attention paid to this class of biomolecules.

In this sense, the present review is aimed at providing detailed information on PS therapeutic potential for human health, moving from preclinical to clinical pharmacological effects, and bioavailability issues.

\section{PRECLINICAL PHARMACOLOGICAL ACTIVITIES OF PHYTOSTEROLS}

Experiments in animals and cell manners have shown that PSs may confer a wide number of biological effects, including chemopreventive, antioxidant, anti-inflammatory, antidiabetic, antiatherosclerotic, and cardioprotective agents (Table 1).

\section{Chemopreventive Effects}

Several studies have reported that PSs possess anticancer properties through interaction with various cell targets and pathways.

Beta-sitosterol isolated from Asclepias curassavica L. was reported to be effective in colorectal cancer in a dose-related 

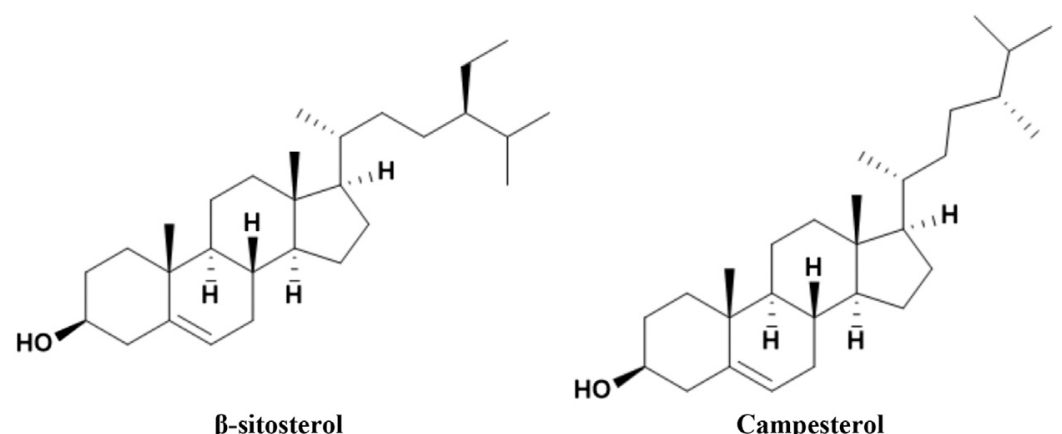

$\beta$-sitosterol

Campesterol

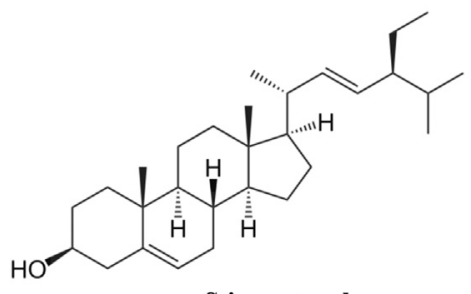

Stigmasterol

FIGURE 2 | The structure of the most occurring plant-originated sterols in human diet.

approach. $\beta$-sitosterol supplementation decreased the number of aberrant crypts and crypt multiplicities in 1,2 dimethylhydrazine (DMH)-initiated rats without exerting toxic effects and also attenuated $\beta$-catenin and proliferating cell nuclear antigen (PCNA) expression in human intestinal carcinoma cells (Baskar et al., 2010). Various experiments have also revealed that $\beta$-sitosterol supplementation is effective in MCF-7 and MDA-MB-231 breast cancer cells, triggering apoptosis by increasing Fas protein expression, caspase 8, and tumor necrosis factor-related apoptosis-inducing ligand (TRAIL) (Daniel et al., 2001; Awad et al., 2007; Herbst et al., 2010). Awad et al. (2000) observed that $\beta$-sitosterol stimulated apoptosis in MDA-MB-231 cells and reduced tumor size through an estrogen-signaling-independent process. In another study, dietary PS supplementation decreased mammary hyperplastic lesions and total tumor burden in female mice fed with a high-fat diet but not in those with a low-fat diet. This was partly explained by the preventative lipoprotein oxidation/inflammation properties of PSs, which was found to be crucial for tumor expansion (Llaverias et al., 2013). $\beta$-sitosterol and daucosterol identified in Grewia tiliaefolia, alone or in combination, had the potential to promote apoptotic death of A549 lung cancer cells by arresting the cell cycle at the $\mathrm{G} 2 / \mathrm{M}$ phase (Rajavel et al., 2017). $\beta$-sitosterol was also found to significantly induce cell viability reduction in cervical cancer cells (HeLa) in a dose-related approach, interfering on DNA fragmentation through the appearance of a sub-G1 cell population (Alvarez-Sala et al., 2019). Cilla and colleagues (Cilla et al., 2015) in a study performed on Caco- 2 cells stated that PSs and $\beta$-Cx, used alone or combined, markedly decreased cell viability through mitochondrial pathway-induced apoptosis.
As main triggers, the authors reported BAD dephosphorylation, mitochondrial depolarization, and caspase 3-dependent PARP cleavage, along with intracellular $\mathrm{Ca}^{2+}$ influx and ROS level raise. Similar findings were stated by López-García and colleagues (LópezGarcía et al., 2017), who found that PSs trigger cell cycle arrest in phase G0/G1 and cell necrosis in Caco-2 cells. In a similar way, Alvarez-Sala and colleagues (Alvarez-Sala et al., 2018a), addressing the PS impact in colon cancer cells (Caco-2 and HT-29 cell lines) used in combination with 5-fluorouracil, stated a pronounced cell cycle arrest at $\mathrm{S}$ phase, induction of apoptosis, and rise in caspases activation.

\section{Antioxidant and Anti-Inflammatory Activities}

Several reports have indicated that PSs possess interesting antioxidant and anti-inflammatory effects. In vitro studies indicated that PSs reduced lipid peroxidation in platelet membranes in the presence of iron (Van Rensburg et al., 2000), with PS antioxidant effects being increasingly related to their high ability to act as free radicals scavenger and stabilizer of cell membranes and even act as a boost for antioxidant enzymes (Van Rensburg et al., 2000; Nashed et al., 2005; Brüll and Mensink, 2009). In addition, the inflammatory process is increasingly related to oxidative stress and reactive oxygen species (ROS) overproduction, so bioactive molecules with pronounced antioxidant effects also have interesting anti-inflammatory potential, and PSs are not an exception. A study performed by López-García and coworkers (López-García et al., 2020) found that a PS-enriched milk-based fruit beverage with/without galactooligosaccharides blocked 
TABLE 1 | Preclinical phytosterol (PS) bioactive effects and the respective mechanisms of action.

\begin{tabular}{|c|c|c|}
\hline Bioactive effects & Mechanism of action & Reference \\
\hline Anticancer & $\begin{array}{l}\text { Decrease the number of aberrant crypt and crypt multiplicity. Attenuate } \\
\text { B-catenin and PCNA expression. Trigger apoptosis, through increasing } \\
\text { Fas protein expression, caspase 8, TRAIL, BAD dephosphorylation, } \\
\text { mitochondrial depolarization and caspase 3-dependent PARP } \\
\text { cleavage, intracellular Ca2+ influx, rise in ROS levels, cell cycle arrest at } \\
\text { phase G0/G1 and S, and cell necrosis } \\
\text { Decrease mammary hyperplastic lesions and total tumor burden } \\
\text { Cell cycle arrest at G2/M phase } \\
\text { Interfere in DNA fragmentation }\end{array}$ & $\begin{array}{l}\text { Daniel et al. (2001); Awad et al. (2007); Baskar et al. (2010); Herbst } \\
\text { et al. (2010); Cilla et al. (2015); López-García et al. (2017); } \\
\text { Alvarez-Sala et al. (2018a) }\end{array}$ \\
\hline Antioxidant & $\begin{array}{l}\text { Free radical scavenger } \\
\text { Cell membranes stabilizer } \\
\text { Antioxidant enzyme booster }\end{array}$ & Van Rensburg et al. (2000) \\
\hline Anti-inflammatory & $\begin{array}{l}\text { Macrophage- and neutrophil-mediated inflammatory process } \\
\text { Evoke Th1 cell response } \\
\text { Decrease edema } \\
\text { Decrease proinflammatory cytokine levels } \\
\text { Interfere in matrix degradation mediators } \\
\text { Increase the remission periods in Gl tract diseases, improving colon } \\
\text { shortening and blocking mucosal colonic damage }\end{array}$ & $\begin{array}{l}\text { Nashed et al. (2005); Brüll and Mensink (2009); López-García et al. } \\
\text { (2019); López-García et al. (2020) }\end{array}$ \\
\hline Antidiabetic & $\begin{array}{l}\text { Glucose metabolism modulation } \\
\text { Interfere with AMPK and peroxisome proliferator-activated receptors }\end{array}$ & Zakłos-Szyda (2015) \\
\hline $\begin{array}{l}\text { Antiatherosclerotic/effects on } \\
\text { lipid profile }\end{array}$ & $\begin{array}{l}\text { Cholesterol absorption blockage } \\
\text { Decrease LDL-C and VLDL secretion and accumulation } \\
\text { Decrease plasma and hepatic TG levels }\end{array}$ & Moghadasian (2000) \\
\hline Neuroactive effects & $\begin{array}{l}\text { Reduce } A \beta \text { plaque formation, counteract memory deficits, increase the } \\
\text { acetylcholine levels in brain, and increase } A \beta \text { clearance }\end{array}$ & Schepers et al. (2020) \\
\hline $\begin{array}{l}\text { Antieryptotic and } \\
\text { antihemolytic effects }\end{array}$ & $\begin{array}{l}\text { Prevent eryptosis; reduce } \mathrm{Ca}^{2+} \text { influx, ROS overproduction, GSH } \\
\text { depletion, and hemolysis }\end{array}$ & Alvarez-Sala et al. (2018d) \\
\hline Microbiota modulation effects & $\begin{array}{l}\text { Promoters of beneficial species abundance, affecting the } \\
\text { Erysipelotrichaceae and Eubacterium family proportions }\end{array}$ & Cuevas-Tena et al. (2018) \\
\hline
\end{tabular}

AMPK, adenosine monophosphate (AMP)-activated kinase; DNA, deoxyribonucleic acid; Gl, gastrointestinal; LDL-c, low-density lipoprotein cholesterol; PCNA, proliferating cell nuclear antigen; PSs, phytosterols; TG, triglycerides; TRAIL, tumor necrosis factor-related apoptosis-inducing ligand; VLDL-C, very-low-density lipoprotein cholesterol.

cholesterol oxidation products oxidation-induced oxidative stress, besides reducing the levels of interleukin (IL)-8 and IL-6 following IL-1 $\beta$-induction. Indeed, PSs have also been revealed to be able to decrease macrophage- and neutrophilmediated inflammatory reaction. In vivo studies in mice have indicated that PSs can evoke a 1Th response and decrease edema and proinflammatory cytokine concentrations (Nashed et al., 2005; Brüll and Mensink, 2009). The effectiveness of PSs in inflammatory bowel disease has also been tested in mice, where PSs feeding did not obstruct colitis onset but considerably decreased the disorder intensity and enhanced clinical remission (Vilahur et al., 2019). A potent antioxidant action was also seen, almost restoring colon, ileal, and gallbladder motility (Aldini et al., 2014). Additionally, PSs were proved to allow homeostatic stability restoration of hepatic and colon metabolism in an experimental colitis mice model (Iaccarino et al., 2019). Similar findings were stated by López-García and colleagues (López-García et al., 2019) following administration of a PS-enriched milk-based fruit beverage in a murine chronic colitis model, where a marked reduction in ulcerative colitisassociated symptoms was stated along with an improvement in colon shortening and mucosal colonic damage.
In vivo studies proved that stigmasterol could inhibit various proinflammatory and matrix degradation mediators involved in triggering osteoarthritis-induced cartilage degrading, at least in part through nuclear factor kappa B (NF-kB) pathway inhibition (Gabay et al., 2010).

\section{Antidiabetic Effects}

Some studies have identified PSs as key modulators of glucose metabolism, through acting on AMP-activated kinase (AMPK) activation or peroxisome proliferator-activated receptors (PPARs) to transcriptional regulation pathways (Zakłos-Szyda, 2015). Hwang et al. have indicated that $\beta$-sitosterol $(20 \mu \mathrm{M})$ handling of L6 muscle cells increases glucose intake across increased GLUT4 translocation to the plasma membrane (Hwang et al., 2008). A limited rise in blood glucose scale after oral administration of high glucose concentration and increased insulin response was observed in Zucker diabetic fatty rats supplemented with 5-campestenone (0.6\%) (Konno et al., 2005). A prominent decrease in blood glucose levels with concurrent glucose elimination inhibition in urine was reported in $\mathrm{db} / \mathrm{db}$ mice fed with $0.3 \% 5$-campestenone after eight weeks (Suzuki et al., 2002). 


\section{Effects on Lipoprotein Metabolism}

In accordance with various surveys, PS administration led to a reduction in total cholesterol (TC) and LDL-C levels by blocking dietary cholesterol absorption and further impacting its hepatic/ intestinal biotransformation (Moghadasian, 2000). Male C57BL/ $6 \mathrm{~J}$ mice with high-fat diet supplementation together with $3.1 \%$ PS administration for three weeks presented a decrease in very-lowdensity lipoprotein (VLDL) secretion, while no distinction was found in chylomicron secretion (Schonewille et al., 2014). Epidemiological and experimental data have affirmed that a high-cholesterol diet is detrimental to cognitive performance in animal models. Rui et al. proved that rats fed with a highcholesterol diet supplemented with $2 \% \mathrm{~g} / 100 \mathrm{~g}$ PS for 6 months maintained body mass match, reduced serum lipid levels, improved cognitive performance, triggered an increase in pyramidal cells number, and had an obvious reduction in the number of astrocytes (Rui et al., 2017).

Several studies have emphasized the role of PSs in plasma and hepatic triglycerides (TG) levels modulation (Rideout et al., 2015b). Rideout et al. assessed the effect of diet supplemented with $2 \% \mathrm{w} / \mathrm{w}$ PSs on Syrian golden hamsters fed with a high-fat diet for 6 weeks (Rideout et al., 2014). Curiously, the decrease in blood TG in the PS group was similar to that using ezetimibe (Rideout et al., 2014). Similar results were found in other animal studies, considering that some factors, such as the type of diet applied, PS dosage, test period, and diurnal regulation of lipid levels, could contribute to the differences observed in TGlowering level and associated mechanisms (Pan et al., 2010; Schonewille et al., 2014). Thus, given the main findings from animal experiments, it was proposed that PSs are able to lower circulating TG levels through mechanisms involving the reduction of TG and FA uptake, a rise in fecal FA excretion, a decrease in duodenal bile acid excretion, and modulation of hepatic FA and TG metabolism (Rideout et al., 2015a). Some in vivo studies with different animal models have delivered conflicting results, such as the case of Brufau et al., who investigated the effect of $2.45 \% \mathrm{~g} / 100 \mathrm{~g}$ PS supplementation on guinea pigs with a high-saturated fat diet for 4 weeks (Brufau et al., 2007). The authors did not state changes in medium chain FAs excretion, but medium/short-chain FA excretion decreased, while an increase in long-chain FA excretions was detected (Brufau et al., 2007). In addition, although total saturated FA fecal excretions did not change, the shift toward greater excretion of longer chain and more hydrophobic saturated FA suggest a reduction in intestinal lipid solubilizing potential, and the study period selected for this experiment may have also affected the obtained results.

\section{Antiatherosclerotic Effects}

Antiatherosclerotic properties of plant sterols are properly developed in several animal models and directly associated with their cholesterol-lowering effects (Jessup et al., 2008). Shariq et al. (2015) studied the antiatherosclerotic effect of virgin coconut oil reported to contain increased levels of PSs on male Wistar rats. The findings revealed a considerable decrease in body weight, TC, TG, LDL, and VLDL and a significant increase in high-density lipoprotein (HDL) levels correlated with antiatherosclerotic effects. Various investigations have also explained a modulatory role for PSs on atherosclerosis due to their anti-inflammatory effects (Nashed et al., 2005; Calpe-Berdiel et al., 2007). PSs were found to reduce proinflammatory cytokine generation, namely, IL- 6 and tumor necrosis factor (TNF)- $\alpha$, and increase the Th1/ Th2 ratio and the level of Treg cytokine IL-10 in splenocytes of $\mathrm{ApoE}^{-/-}$mice (Nashed et al., 2005; Calpe-Berdiel et al., 2007). Increased serum IL-10 levels have also been correlated with a severe reduction in atherosclerotic lesion size (Pinderski et al., 2002; Nashed et al., 2005). A marked reduction in atherosclerotic lesions size was also linked to a prominent reduction in other constituents, such as the number of foam cells and cholesterol clefts, extracellular matrix amounts, and the extent of apparently proliferative smooth muscle cells (Moghadasian, 2000). ApoEdeficient mice fed on a diet supplementation with $2 \%$ PS for 14 weeks led to changes in the expression of 132 genes, with particular emphasis on hepatic genes involved in sterol biotransformation regulation (Xu et al., 2008). All these changes allow a better understanding of how PSs mechanistically exert their cardioprotective action.

\section{Other Effects}

Besides the above listed biological activities of PSs, some recently published studies have also underlined interesting effects, namely, to what concerns to its antieryptotic and antihemolytic effects and neuroprotective and even microbiota modulatory abilities. In an in vitro study, Alvarez-Sala and colleagues used a selected PS mixture, composed of $\beta$-sitosterol, campesterol, stigmasterol, or $\beta$-cryptoxanthin $(\beta-\mathrm{Cx})$, and observed that the use of $\beta$-Cx led to an increase in eryptotic cell number and volume, hemolysis, and glutathione depletion (GSH) without ROS overproduction and intracellular $\mathrm{Ca}^{2+}$ influx (Alvarez-Sala et al., 2018d). On the other side, PSs prevented eryptosis, reduced $\mathrm{Ca}^{2+}$ influx, ROS overproduction, GSH depletion, and hemolysis. However, when both bioactive compounds were coincubated, they completely prevented hemolysis, prevented eryptosis and GSH depletion, and thus may be considered promissory candidates for eryptosis-associated disease healing.

In another study, Cuevas-Tena et al. (2018) assessed the plant sterol influence on gut microbiota and vice versa. As main findings, the authors stated that both Erysipelotrichaceae and Eubacterium family proportions were affected by high-dose plant sterols, at the same time that sitosterol and stigmasterol decreased while its metabolites increased. Concomitantly, low TC conversion was stated under plant sterols presence. Thus, plant sterols may be viewed as promoters of beneficial species abundance (Cuevas-Tena et al., 2018).

More recently, Schepers et al. (2020) highlighted in a review article prominent neuroactive effects of PSs derived from marine origin. As main statements, the authors clearly highlighted the ability of fucosterol, 24(S)-saringosterol, sitosterol, and stigmasterol to reduce $\mathrm{A} \beta$ plaque formation; the ability of fucosterol and 24(S)-saringosterol to counteracts memory deficits; the ability of fucosterol to increase the acetylcholine levels in the brain; and the ability of 24(S)-saringosterol to increase $A \beta$ clearance (Schepers et al., 2020). 


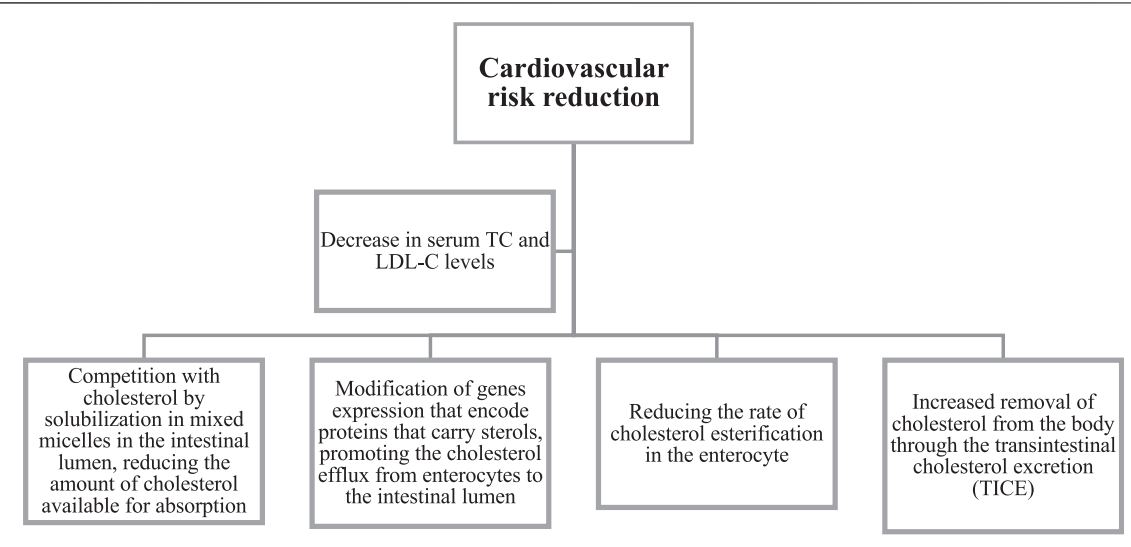

FIGURE 3 | Mechanism of action of phytosterols in reducing cardiovascular diseases.

\section{Adverse Effects}

Specifically addressing the possible adverse effects related to PSs, first, it is worth noting that in vitro studies have shown that high $\beta$-sitosterol amounts can trigger human umbilical vein endothelial cells shrinking (Rubis et al., 2008). Second, particularly addressing in vivo studies, it should be highlighted that some animal species, such as rodents, may not represent a proper prototype due to the remarkable variations between them and humans in sterol metabolic process (Dietschy and Turley, 2002), although several animal studies have indicated possible undesirable adverse effects of PSs. For example, Chen et al. reported that WKY inbred rats consuming diets containing PSs or phytostanol had a notable rise in systolic and diastolic blood pressure correlated with increased renal angiotensinogen mRNA levels (Chen et al., 2010). Wild-type mice fed with PS or phytostanol diets also showed impaired endothelium-dependent vasorelaxation and grown cerebral lesion area after middle cerebral artery occlusion (Weingartner et al., 2008). In addition, high PS concentrations in plasma of both male and female laboratory animals may have adverse effects on their generative organs (Malini and Vanithakumari, 1990). In rats, both testosterone and estradiol levels in males and females, respectively, were also raised due to $\beta$-sitosterol intake (Ryokkynen et al., 2005).

On the other hand, it is also convenient to highlight that plants often accommodate traceable amounts of oxidized derivatives of PSs (oxyPS). These compounds are noticeable in atheromatous plaque, and this may demonstrate their engagement in atherosclerosis expansion (Patel and Thompson, 2006). However, the number of investigations conducted so far is not acceptable to assess the exact metabolic action of oxyPS. In such a way, a recent study published by Alvarez-Sala and colleagues (Alvarez-Sala et al., 2018b) measured both the level of oxidized sterols formed and its bioaccessibility in a plant sterol-enriched milk-based fruit beverage with milk fat globule membrane at 0-, 3-, and 6-month storage. As main findings, the authors did not state considerable changes during storage, meaning that such formulation was maintained stable over the studied period, without an increase in oxidized sterols' contents and bioaccessibility, and thus may be considered as a suitable PS-enriched food matrix for extended shelf-life, in addition of being safe for consumers (Alvarez-Sala et al., 2018b). Nonetheless, the authors just assessed a single preparation, and thus further studies are still needed in such a way.

\section{PHYTOSTEROLS IN CLINICAL TRIALS}

\section{Phytosterols and Cardiovascular Risk}

A plethora of studies have explored distinct aspects of the clinical efficacy of plant sterols/stanols in lowering LDL-C levels. There have been more than five decades of research on PSs to prove its efficacy in decreasing cholesterol levels. It was shown that PSs inhibit cholesterol intake via cholesterol displacement from micelles (Ling and Jones, 1995), thus reducing the risk of CV diseases (Vahouny et al., 1983; Ikeda et al., 1988) (Figure 3).

A survey of 46 patients (Lees et al., 1977) with type II hyperlipoproteinemia was conducted to evaluate the effect of plant sterols preparations from two distinct sources and in two physical forms in lowering plasma TC levels, administered along with appropriate diet therapy. The PS hypocholesterolemic potential was also assessed in seven patients by a sterol balance technique, revealing inhibition of TC intake. The maximal mean TC lowering was $12 \%$, which suggests the PS potential value as a dietary therapy adjunct in mild hypercholesterolemic patients (Lees et al., 1977).

A clinical trial performed in 153 mild hypercholesterolemic patients revealed that substituting sitostanol-ester margarine as part of the normal daily dietary fat is effective in lowering serum TC and LDL-C, thus having favorable effects (Miettinen et al., 1995). Another report summarizing information from a meta-analysis of 41 trials on sterols and stanols efficacy and safety profile demonstrated that consumption of $2 \mathrm{~g} / \mathrm{d}$ of stanols or sterols decreased LDL-C by $10 \%$ (Katan et al., 2003). Epidemiological studies with TClowering drugs showed that its long-term use in the first five years reduces the CV disease risk by $12 \%-20 \%$, whereas 
lifetime use reduces it by $20 \%$. Additionally, the adverse effects of plant sterols intake into blood circulation were found to be hypothetical in adults. This study agrees with another metaanalysis of 59 clinical trials (Abumweis et al., 2008), where plant sterols (and stanols)-containing product use when compared to placebo was linked to a reduction in LDL-C levels. An investigation performed to evaluate the PS role in changing plasma lipid levels, when incorporated into nonfat or low-fat beverages on moderately hypercholesterolemic men and women (Jones et al., 2003), revealed that PS absorption in the low-fat beverage format is not effective in changing the lipid levels, namely, HDL-C and triacylglycerol (TAG).

While earlier no significant changes in TG levels were documented with the use of stanols and sterols, some metaanalyses have reported a small, but statistically significant decrease in TAG levels (Gupta et al., 2011). Moreover, it has been found that the daily use of 1.6-3 $\mathrm{g}$ of esterified PS in the first month of therapy reduces LDL-C levels by $4.1-15 \%$ when compared to placebo (O'neill et al., 2005).

In a clinical study assessing the effects of plant stanol and sterol esters on serum PS levels in individuals with familial hypercholesterolemia, a reduction in serum TC levels was documented, although the clinical role of increased plant sterol contents was not known (Ketomaki et al., 2004). In a nine-week trial with metabolic syndrome patients receiving a daily dose of $2 \mathrm{~g}$ stanol esters, a remarkable decline in non-HDL-C and TAG levels was documented (Plat et al., 2009). Moreover, the TAG effects were also present in combination with a low dose $(10 \mathrm{mg})$ simvastatin treatment, thus depicting the additional benefit of stanol esters use in individuals with $\mathrm{CV}$ disease risk.

In another study, the effects of the absorption of three phytosterols on whole-body TC metabolic pathway were determined in 18 adults receiving a phytosterol-deficient diet (50 mg PS/2000 kcal) plus beverages supplemented with 0,400 , or $2000 \mathrm{mg}$ PS/day for four weeks each in a random order (Racette et al., 2010). Dietary PS, at moderate $(459 \mathrm{mg} /$ day) and high (2059 mg/day) dosages, dose-dependently improved biliary and dietary TC excretion and decreased the efficiency of intestinal TC absorption. In another study, this group of researchers also reported a significant reduction in intestinal TC absorption and an increased fecal TC excretion during ezetimibe administration plus plant sterols ( $2 \mathrm{~g} /$ day) when compared to ezetimibe alone (Lin et al., 2011). This data indicates that PS combination with ezetimibe notably improved the ezetimibe effects, thus emphasizing the dietary importance of PS as adjunctive therapy for hypercholesterolemia. In addition, it has been reported that the effective daily dose range of PS is between $1 \mathrm{~g}$ and $3 \mathrm{~g}$, beyond which it offers no additional benefits and fully effective therapy can take up to eight weeks (Malinowski and Gehret, 2010).

Another clinical study with 41 men and women designed to explore the activity of PS capsules on circulating LDL-C levels in patients with mild-to-moderate hypercholesterolemia revealed that daily PS intake in capsules ( $2 \mathrm{~g}$ ) did not decline TC or LDL-C levels (Ottestad et al., 2013). These findings emphasize the need for choosing a suitable dose delivery system to reach optimal TClowering effects.
A clinical trial with 182 hypercholesterolemic adults was performed to assess the long-term effectiveness of $2 \mathrm{~g} /$ day of plant stanols for 12 months in reducing LDL-C levels (ParragaMartinez et al., 2015). As main findings, $>10 \%$ reduction in plasma LDL-C levels was stated from baseline at both three months and one year of consumption, hinting its role in reducing $\mathrm{CV}$ disease risk.

As plant sterols have been reported to reduce plasma LDL-C, a double-blind randomized placebo-controlled parallel-group study was performed in hypercholesterolemic patients (Ras et al., 2013). Healthy men and women used low-fat spreads without or with added PS (3g/d) for 12 weeks after a fourweek run-in period (Ras et al., 2013). The time curves of changes in plasma PS for 12 weeks of PS intake and the impact of TC synthesis and absorption in plasma PS were also exploited. The authors stated a plasma PS levels stabilization within four weeks of PS intervention, which were not impacted by basal TC synthesis or absorption efficiency.

Due to the high prevalence of lactose intolerance in China, a study was designed to evaluate if PS-rich milk is effective in lowering serum LDL-C (Cheung et al., 2017). Other participants $(n=221)$ without TC-lowering drugs or diabetes mellitus were assigned to a daily intake of PS-rich low-fat milk, containing $1.5 \mathrm{~g} \mathrm{PS} /$ day or conventional low-fat milk for three weeks. Blood profile and physical examination were also performed. As compared to control, the treated group depicted a remarkable decline in serum LDL-C and TC levels and diastolic blood pressure; thus, it can be used as part of a healthy diet.

A three-arm, double-blind, randomized clinical trial in mildly hypercholesterolemic subjects was conducted to analyze the effects of PSs, red yeast rice, or both nutraceuticals on lipid pattern over an 8-week treatment period, as well as their tolerability (Cicero et al., 2017). It was documented that the additive lipid-lowering effect of PSs and red yeast rice enhanced lipid parameters with good short-term tolerability as depicted by a significant reduction in LDL-C and apolipoprotein B levels comparing with individual treatments of these two nutraceuticals. In addition, a double-blind randomized placebo-controlled crossover intervention study was performed with healthy volunteers (without or mild hypercholesteremia) to assess the activity of plant sterol esters supplemented margarine on TC, non-TC sterols, and oxidative stress in serum and monocytes (Weingartner et al., 2017). The authors stated that plant sterol ester consumption supplemented margarine led to a rise in plant sterol contents and TC synthesis markers, without affecting serum TC and activating circulating monocytes or redox state (Weingartner et al., 2017).

Considering the high occurrence of nonalcoholic fatty liver, the role of dietary cholesterol in liver inflammation, and the PS action on TC metabolism, the PS therapeutic potential against nonalcoholic fatty liver disease has also been explored (Javanmardi et al., 2018). It has been documented that, as compared to the placebo, PS additive remarkably enhanced LDL-C, aspartate aminotransferase, alanine aminotransferase, and TNF- $\alpha$ levels. However, no remarkable differences were stated between the two groups with regard to TC, TG, HDL-C, VLDL-C, LDL-C/HDL-C, and TC/HDL-C 
ratios, gamma-glutamyl transferase, IL-6, high-sensitivity C-reactive protein (hs-CRP), adiponectin, and leptin levels.

The effect of dietary intervention with PSs, with or without curcumin, on blood lipids in hypercholesterolemic individuals was also investigated in a double-blind, randomized, placebo-controlled, $2 \times 2$ factorial trial (Ferguson et al., 2018). The authors documented that curcumin addition to PS therapy led to a complementary TClowering effect, larger than PS therapy alone without adverse effects. Another study assessed the TC-lowering activity of $2 \mathrm{~g}$ of plant sterols from sterol-rich cereals through the form of a whole grain wheat biscuit, in 50 volunteers with a $\mathrm{TC}>5.5 \mathrm{mmol} / \mathrm{L}$ in a randomized crossover trial with two four-week periods (Clifton and Keogh, 2018). It was observed that the LDL-C lowering effect of the whole grain wheat biscuit did not vary from other foodstuff delivering 2-2.5 g of plant sterols daily. Recently, a study assessed the gender differences in LDL-C lowering activity post-PS intervention (San Mauro-Martín et al., 2018), where milk intake with $2.2 \mathrm{~g}$ /day of added PSs significantly lowered LDL-C levels in men. In studies on prepubertal children with familial hypercholesterolemia, dietary plant sterol/stanol consumption did not ameliorate endothelial function despite the significant decrease in LDL-C levels (De Jongh et al., 2003; Jakulj et al., 2006). Interestingly, some early reports have documented that the mildly elevated plant sterol levels are positively impacted with vascular disease (Sudhop et al., 2002; Assmann et al., 2006), whereas others referred to an inverse or even lack of association between circulating plant sterols and CV disease risk (Windler et al., 2009; Escurriol et al., 2010). Such variations in PS effects have been increasingly exploited in a tentative way of clarifying the different findings obtained by different authors (Borel and Desmarchelier, 2018). Some recent studies have found variations in both PS absorption and consequent bioavailability, attributed to genetic polymorphisms, namely, that of ABCG5/G8, as other proteins/genes directly or indirectly involved in PS transportation to enterocyte, blood, and even other tissues. Moreover, variations in both Niemann-Pick C1 Like 1 transporter (NPC1L1) and apolipoprotein E (APOE) have also been reported as having a great impact on PS bioavailability (Borel and Desmarchelier, 2018). More detailed attention is given in the section PS bioavailability.

\section{Phytosterols and Cancer Risk}

Dietary and lifestyle factors play a critical role in cancer etiology. PSs are well recognized for their role in maintaining blood TC levels, but their potential in the area of anticancer research is still unexplored, with case-control studies showing no causal effect (Figure 4). For example, a randomized, double-blind, placebocontrolled multicenter trial in patients with benign prostatic hyperplasia $(\mathrm{BPH})$ was performed over 6 months, using $\beta$-sitosterol (which contains a mixture of PSs) three times/day or placebo (Berges et al., 1995). Although no relevant decline in prostatic volume was observed in the $\beta$-sitosterol and placebo group, a remarkable improvement was seen in symptoms and urinary flow parameters, revealing the $\beta$-sitosterol effectiveness. Similar results were reported in another clinical study, using the $\beta$-sitosterol for the treatment of $\mathrm{BPH}$, where results demonstrated slightly more rapid changes than that stated by Berges et al., (1995) with a difference of 2.6 points over placebo after four weeks (Klippel et al., 1997). A case-control study was also performed to determine the protective role of plant sterols in lung carcinogenesis in 463 subjects (Mendilaharsu et al., 1998). It was concluded that the highest quartile intake of PSs led to a $50 \%$ reduction in lung cancer risk. Another case-control study found that the highest PS intake is inversely related to gastric cancer risk (De Stefani et al., 2000).

Looking at ovarian cancer, a case-control study was conducted in 124 confirmed ovarian cancer cases to determine the impact of food diet, via a detailed food frequency questionnaire (Mccann et al., 2003). As compared with women in the lowest quintile of intake, a lower risk was documented for women in the highest quintile of stigmasterol intake, thus supporting the assumption that phytoestrogen intake exerts a protective action on ovarian cancer (Mccann et al., 2003). Conversely, in a cohort study on 3,123 subjects with colon and rectal cancer risks, no association was observed between PS intake and a lower risk of colon and rectal cancers (Normen et al., 2001). Moreover, a recently published meta-analysis aiming to provide a comprehensive synopsis on PS intake and cancer risk highlighted a linear association for campesterol and a nonlinear association for total PS intake and cancer risk. Such findings support that high PS intake is inversely related to cancer risk, although further and more in-depth studies are needed, particularly of prospective design to more clearly know the PS contribution to anticancer effects (Jiang et al., 2019).

\section{Phytosterols and Gestational Diabetes}

Gestational diabetes mellitus (GDM) is a rapidly growing serious health complication over pregnancy. A clinical study designed to assess the action of a PS-rich margarine spread daily consumed on insulin resistance and lipid profile in GDM women revealed that, after 16 weeks, TAG, TC, and LDL-C levels were remarkably reduced, while HDL-C increased when compared to baseline ( $\mathrm{Li}$ and Xing, 2016). Additionally, fasting plasma glucose and serum insulin levels, insulin check index, and $\beta$-cell function were also remarkably improved. In another clinical study, the effect of PS-rich margarine spreads consumed daily was assessed on both maternal and neonatal outcomes of GDM patients (Gao et al., 2017). It was observed that the daily consumption of the PS-rich spread led to remarkable benefits on maternal diabetic symptoms, namely, in improving lipid composition and glucose metabolism and decreasing the incidence of neonatal complications.

\section{Phytosterols and Immunomodulation}

Although the role of PSs in immunomodulation has not yet been extensively exploited, studies have suggested their impact on the immune system, via T cells (Bouic, 2001) (Figure 5). Thus, to assess the effects of acute plant stanol esters intake on gene profile expression of the upper small intestine in healthy volunteers, a double-blind crossover design was performed in 14 healthy subjects (De Smet et al., 2015). Microarray analysis showed that the acute plant stanol esters intake did not change genes profiles expression. Nevertheless, T-cell functioninvolved pathways were consistently downregulated in the 


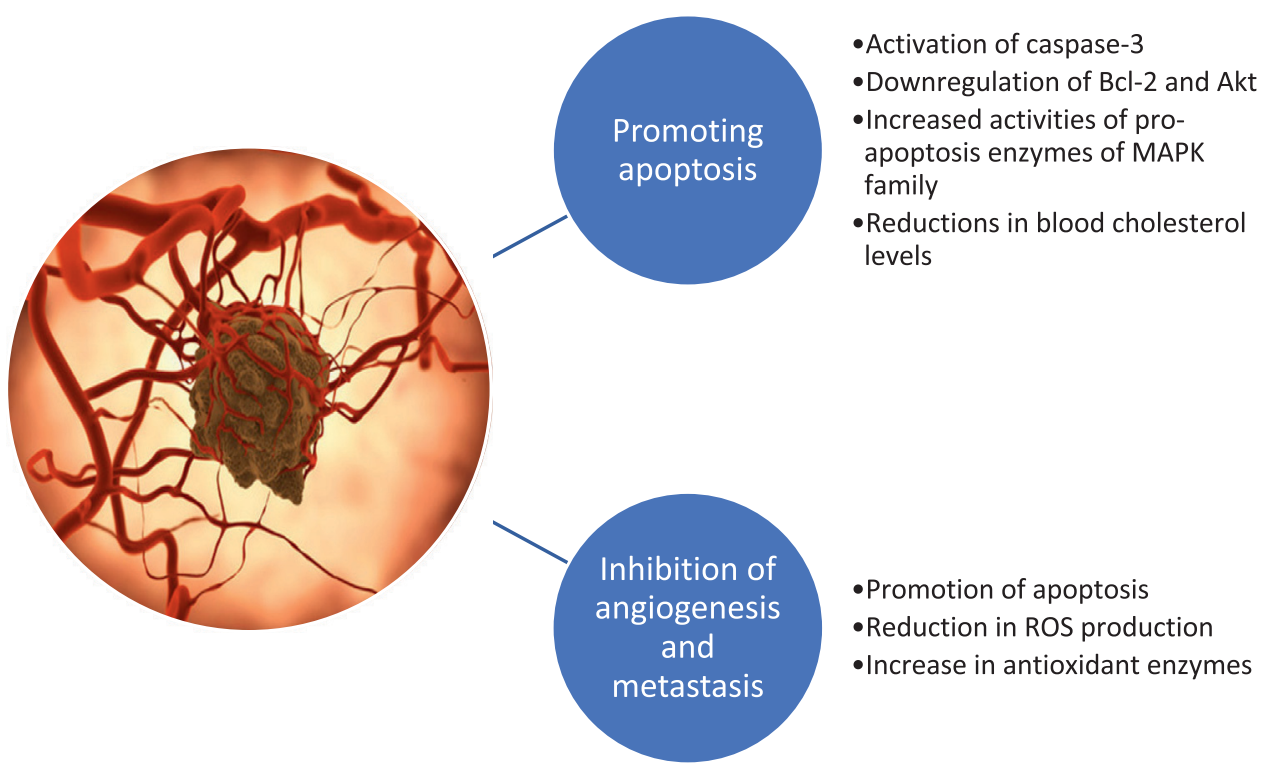

FIGURE 4 | Anticancer effects of phytosterols.

jejunum. In vitro and ex vivo investigations have demonstrated that plant sterols and stanols can shift the T helper (Th) 1/Th2 balance toward a Th1-type immune response, which may be beneficent in Th2-dominant conditions, such as asthma and allergies. In another study, the effects of plant stanol esters on the immune response of asthma patients were assessed (Brüll et al., 2016). For that, 58 asthmatic patients were recruited, with half of them receiving plant stanol-rich soy-based yogurts ( $4.0 \mathrm{~g}$ plant stanols/day), while the others consumed control yogurts (Brüll et al., 2016). It was found that asthmatic patients receiving plant stanol-rich soy-based yogurts had higher antibody titers against hepatitis A virus (3 and 4 weeks after vaccination) and marked reductions in plasma total Ig-E, IL$1 \beta$, and TNF- $\alpha$ levels (Brüll et al., 2016); thus, plant stanol ester consumption was able to improve the immune function in asthmatic patients. More recently, Alvarez-Sala et al. (2018a) assessed the impact of a milk-based fruit beverage with a milk fat globule membrane on the levels of cholesterol and cholesterol precursors, serum biomarkers, and cytokines in postmenopausal women. As main findings, the authors stated a marked decrease in TC and LDL levels and a marked increase in the precursor lanosterol with a concomitant decrease in the proinflammatory cytokine IL- $1 \beta$; such observations clearly underline that this beverage may promote the $\mathrm{CV}$ health in postmenopausal women given its impact on both inflammatory status and CV risk factors (Alvarez-Sala et al., 2018c).

\section{Phytosterols and Osteoporosis}

A clinical trial analyzed the effect of $\beta$-Cx plus PSs on CV risk and bone turnover markers in postmenopausal women, who are at higher risk of CV disease and bone demineralization (Granado-
Lorencio et al., 2014). Interestingly, it was observed that $\beta$-Cx enhances the TC-lowering action of PSs when simultaneously supplied with this combination providing benefits in reducing the risk of osteoporosis.

The clinical trials of PSs performed on CV risk, cancer risk, gestational diabetes, immunomodulation, and osteoporosis are summarized in Table 2.

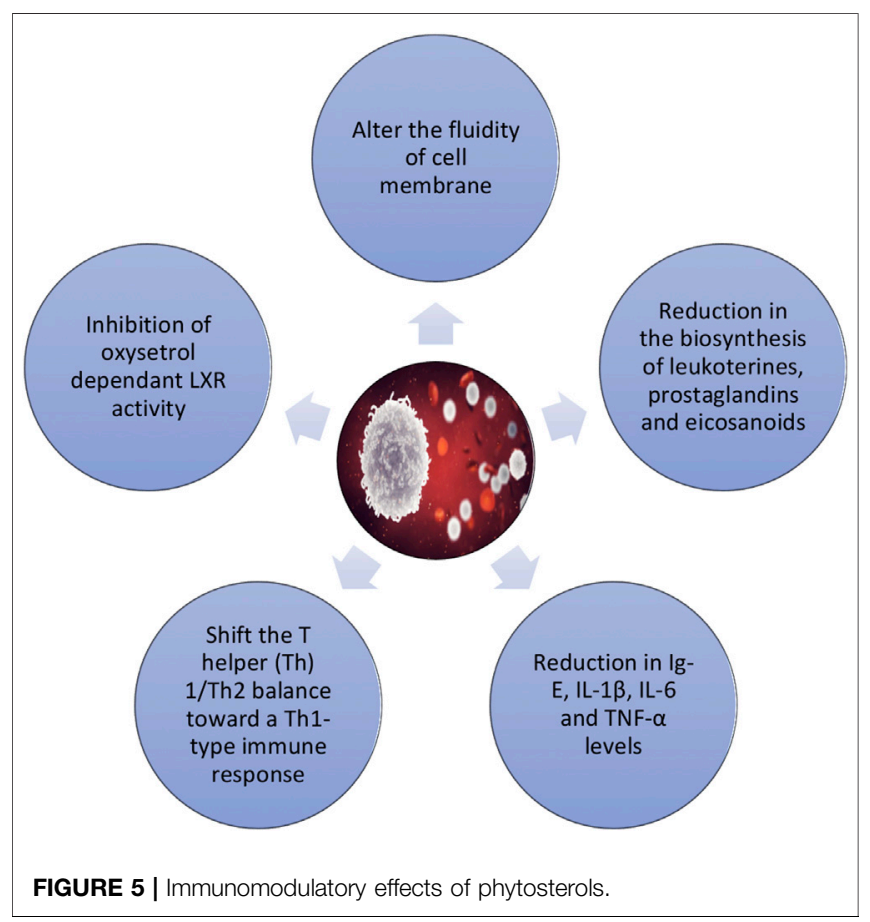




\section{BIOAVAILABILITY OF PHYTOSTEROLS}

PSs are absorbed from food in the proximal small bowel and incorporated into micelles (Salen et al., 2006; Miras-Moreno et al., 2016). At the same time, the PS absorption is lesser than that of cholesterol, because of intestinal lumen selectivity and return, through an ABC-transporter-mediated process. Only a small amount of PSs administered with food is absorbed and reaches the systemic circulation (Ostlund et al., 2002). In addition, PSs are not produced in the human organism, and the concentration of PSs circulating in the human body is two hundred times less than that of cholesterol in subjects with the usual type of nutrition (Chan et al., 2006; Ras et al., 2013).

According to Miettinen et al. (1990), the content of plant sterols in human blood is only $0.1-0.14 \%$ of TC level. In a healthy human, sitosterol/cholesterol ratio on a molar basis is around 1 to 800-1,000 (Shahzad et al., 2017). Mellies et al. (1976) found that $300-900 \mathrm{mg} /$ day of plant sterol consumption with food led to a significant amassing in plasma $(0.44 \mu \mathrm{M})$ of children (Mellies et al., 1976).

In some studies, it appeared that plant sterol conversion to stanols significantly reduces LDL-C serum levels (Ikeda and Sugano, 1978; Sugano et al., 1978; Becker et al., 1993). Since nonesterified stanols may have restricted bioavailability to block cholesterol intake (Denke, 1995), a trial was made to increase their bioavailability by converting nonesterified bioavailable stanols into FA stanol esters (Heinemann et al., 1986). Plant stanols esters can easily dissolve in oils or margarine. They suffer intestinal hydrolysis, releasing nonesterified stanols bioavailable to block cholesterol absorption in the intestine.

\section{In Vitro Phytosterol Bioavailability}

Baldi and Pinotti reported that milk fat is an effective delivery system for highly hydrophobic compounds, such as PSs (Baldi and Pinotti, 2008). In addition, the occurrence of lecithin or unsaturated FA (oleic, linoleic, and $a$-linolenic acids) (Brown et al., 2010) may improve cholesterol and/or PS inclusion in a micelle-mixed bile model.

Some studies have also focused on sterols solubility assessment after digestion product imitation containing orange juice enriched with PS or multivitamin/multimineral tablets dissolved in orange juice (Bohn et al., 2007), PS-rich commercially available fermented milk beverages (Vaghini et al., 2016), and skimmed milk and/or fruit beverages. Data show that both matrix and component composition of PSs present in food have a key effect on their bioavailability. For example, Alvarez-Sala et al. developed a functional milk-based fruit drink with PSs modified with lipid components/emulsifiers to increase PS bioavailability. The authors found that the content of the sum and individual PSs, fat, type of emulsifier, and homogeneity in beverages differed (Alvarez-Sala et al., 2016). Individual PSs in one and the same beverage showed a similar bioavailability, except the beverage without fat addition, where the highest bioavailability corresponded to campestanol. In the beverage, with olive oil and soy lecithin inclusion (where there was less homogeneity), stigmasterol had the lowest bioavailability. Beverages with higher fat content (2.4\%) revealed higher PS bioavailability $(31.4 \%$ and $28.2 \%$, respectively) compared to those where the fat content was $1.1 \%(8.7 \%)$. According to the authors, the fat content in the food matrix may contribute to mixed micelles formation during gastrointestinal (GI) digestion. In general, data showed that PS bioavailability is influenced by both fat type/amount and the type of emulsifier used (Alvarez-Sala et al., 2016). In addition, milk fat and whey proteins addition increase the bioavailability of both the sum and individual PSs, in particular, campestanol, and stigmasterol (Alvarez-Sala et al., 2016).

Nik et al. found in a simulated digestion model in the duodenum that $\beta$-sitosterol, campesterol, and stigmasterol bioavailability (transfer to the aqueous micellar phase) ranged from 72 to $93 \%$ (Nik et al., 2011). These data were higher than that reported in another study (Alvarez-Sala et al., 2016), possibly due to a less complex food matrix.

Vaghini et al. and colleagues investigated the bioavailability of both selected plant sterols and stanols from four (A-D) commercial fermented milk drinks using in vitro GI digestion, including mixed micelles formation. PS amount in beverage samples ranged from $1.5 \%$ to $2.9 \%(\mathrm{w} / \mathrm{w}) . \beta$-sitosterol was present in all samples but prevailed in samples A and B (about $80 \%$ of the total PS number) (Vaghini et al., 2016). Campesterol concentration in the samples was as follows: C $(22 \%)>\mathrm{A}(7 \%)>\mathrm{B}(5 \%)$. Sitosterol was the most common in sample D (85\%), while stigmasterol was only present in sample C (33\%). The highest degree of bioavailability in the PS sum was related to samples A and B (16-17\%), followed by D (11\%) and C (9\%). The PS sum bioavailability was not related to protein, lipids, or PS content in beverages, while in samples with higher carbohydrates and fiber content, bioavailability was lower. The individual PS bioavailability differed relatively to the sample and was not related to sample's PS profile, indicating a high dependence on food matrix composition.

Studies searching for mutations that cause sitosterolemia were original research aiming to identify genetical variations associated with PS bioavailability. Findings from these studies allowed us to associate this disorder with mutations in ABCG5 and ABCG8 genes, encoding 2 ATP-binding cassettes (sterolin-1 and -2) acting as hemitransporters (Borel and Desmarchelier, 2018). These proteins are responsible for PS removal from enterocytes into enteral lumen and hepatocytes from bile. This finding indicates that genetic polymorphisms in these genes may modulate PS bioavailability, although probably less; therefore, it is asymptomatic. This has been confirmed by several associative studies (Borel and Desmarchelier, 2018). However, these results do not present definitive evidence that single nucleotide polymorphisms in these transporters affect the intestinal PS absorption. It seems feasible that the observed associations may be due to the PS effects on hepatocyte excretion but not on enterocytes. Other authors also showed that single nucleotide polymorphisms in ABCG8 can modulate changes in PS content in the blood, thus affecting their bioavailability (Borel and Desmarchelier, 2018).

PS bioavailability is not only controlled by ABCG5/G8, as other proteins/genes directly or indirectly participate in PS transportation through the enterocyte, as well as into the 
TABLE 2 | Clinical studies with PS effects in humans.

\section{Disease/reference}

Cardiovascular risk

Treatment

Outcomes

Lees et al.

CT type II hyperlipoproteinemic patients $(n=46)$. Duration: 7 years

Miettinen et al.

RCT mild hypercholesterolemic patients $(n=153)$. Duration: one year

Jones et al.

Ketomaki et al.

Plat et al.

Racette et al.

Lin et al.

Ottestad et al.

CT moderately hypercholesterolemic patients (men and women; $n=15)$. Duration: 21 days

CT family with familial hypercholesterolemia. Duration: 3-4 weeks

RCT metabolic syndrome patients $(n=36)$. Duration: 9 weeks

CT adults receiving a PS-deficient diet (50 mg

PS/200 kcal), supplemented with different PS doses

$(n=18)$. Duration: 4 weeks

RCT mildly hypercholesterolemic subjects $(n=21)$ Duration: 3 weeks

RCT mild-to-moderate hypercholesterolemic patients Soft gel capsules containing either PS

( $n=41$ men and women). Duration:

$2 \times 4$ weeks

Parraga-Martinez et al. RCT hypercholesterolemic adult patients

$n=182$ ). Duration: 12 months

Cheung et al.

RCT adults $(n=221)$ without TC-lowering drugs or diabetes mellitus ( 41 men and 180 women). Duration: 3 weeks

Cicero et al.

RCT mild-to-moderate hypercholesterolemic subjects $(n=90)$. Duration: 8 weeks

Weingartner et al RCT healthy volunteers, with no or mild hypercholesterolemia $(n=16)$. Duration: 4 weeks

Javanmardi et al.

RCT nonalcoholic fatty liver disease patients $(n=38)$. Duration: 8 weeks

Ferguson et al.

RCT hypercholesterolemic individuals $(n=70)$.

Duration: four weeks powder (3 g/day))

and $2.6 \mathrm{~g} /$ day) and margarine

without sitostanol $(n=51)$

onfat placebo and nonfat and low-fat beverages with added PS simvastatin + stanol drink $(n=8)$

PS-controlled diet plus (1) ezetimib placebo + PS placebo (3) 10 ezetimibe/day + PS par

$2.0 \mathrm{~g} / \mathrm{d}$ ) or sunflower oil $(n=111)$

or both combined nutraceuticals margarine

PS group $(n=19$, received $1.6 \mathrm{~g}$ PS starch daily) $(n=17,2 \mathrm{~g} /$ day), curcumin $(n=18$
Plant sterols preparations from two distinct sources and in 2 physical forms (soy sterols

(18 g/day) and powder (18 g/day) and tail oil terols suspension ( 3 and $6 \mathrm{~g} /$ day) and

tanol-ester margarine $(n=102 ; 1.8$

and $14.1 \%$ decrease in serum TC and LDL-C levels in the sitostanol group and $0.1 \%$ and $1.1 \%$ in the control group, respectively $(p<0.001)$

PS absorption in the low-fat and nonfat beverages was not effective in changing HDL-C and triacylglycerol levels

( $n=9)$, simvastatin + placebo drink $=10)$, placebo + stanol drink $(n=9)$, and Three PS doses (59, 459, 2059 mg PS/day)

Plant stanols (2 g/day) group and control group (receiving unsupplemented yogurt)

PS-rich low-fat milk, containing $1.5 \mathrm{~g} P S / d a y$ $(n=110)$ or a conventional low-fat milk

Stanol esters ( $2 \mathrm{~g} /$ day), simvastatin, or the combination decreased non-HDL-C $(p<0.001)$ and TAG $(p<0.01)$ levels; additional benefits were also seen when stano esters were combined with simvastatin

Moderate (459 mg/day) and high (2059 mg/day) dosages, dose-dependently

improved biliary and dietary TC excretion $(p<0.01)$, and decreased intestinal TC absorption efficiency $(p<0.01)$

Reduction in intestinal TC absorption $(p<0.0001)$ and an increased fecal TC excretion $(p<0.0001)$ during ezetimibe administration plus PS, when compared to ezetimibe alone

Daily PS intake in capsules did not decline TC $(p=0.74)$ or LDL-C $(p=0.32)$ levels

$>10 \%$ reduction in plasma LDL-C levels was stated $(p=0.011)$ from baseline at both three months and one year of plant stanols consumption

PS group revealed a marked decline in serum LDL-C $(-9.5 \%$

$p<0.001)$, TC levels $(p<0.001)$, and diastolic blood pressure $(p=0.01)$

Plant sterols ( $3 \mathrm{~g} /$ day) via a supplemented supplement) and control group $(n=19,1.6 \mathrm{~g}$

Placebo ( $n=18$, no PS or curcumin), PS $200 \mathrm{mg} /$ day), and PS + curcumin ( $2 \mathrm{~g} /$ day $200 \mathrm{mg} / \mathrm{day}$
Additive lipid-lowering effect of PS and red yeast rice enhanced lipid parameters with a marked reduction in LDL-C $(-20.5 \%, p<0.001)$ and apolipoprotein B $(-14.4 \%$, $\rho<0.001)$ levels compared with individual treatments of these two nutraceuticals Plant sterols led to a rise in serum levels of plant sterols (campesterol, $p=0.005$ sitosterol, $p<0.001$ ) and of TC synthesis (desmosterol, $p=0.006$; lathosterol, $p=0.012$ ) markers, without affecting serum TC and activating circulating monocytes or redox state

Compared to placebo, PS group remarkably enhanced LDL-C

$p=0.030)$, AST $(p=0.010)$, ALT $(p=0.001)$, and TNF- $\alpha(p=0.006)$ levels. No differences were stated between the two groups with regard to TC, TG, HDL-C, VLDL-C, LDL-C/HDL-C, and TC/HDL-C ratios, gamma-glutamyl transferase, IL-6, hs-CRP, adiponectin, and leptin levels

Curcumin addition to PS led to a complementary TC-lowering effect, larger than PS therapy alone $(p<0.0001)$, with no adverse effects 


\section{Disease/reference}

Clifton et al. RCT volunteers with a TC $>5.5 \mathrm{mmol} / \mathrm{L}(n=50)$ Duration: $2 \times 4$ weeks

San Mauro-Marín et al. RCT gender differences in LDL-C lowering activity of PS ( $n=30$ women and 24 men). Duration: $2 \times 3$ weeks

\section{Cancer}

Berges et al.

RCT patients with benign prostatic hyperplasia $(n=200)$. Duration: 6 months

Klippel et al. RCT patients with benign prostatic hyperplasia $(n=177)$. Duration: 6 months

Mendilaharsu et al. $\quad$ CCS lung cancer cases $(n=463)$ and hospitalized controls $(n=465)$. Duration: 3 years

De Stefani et al.

CCS gastric cancer cases $(n=120)$ and controls $(n=360)$. Duration: 2 years

McCann et al.

Normen et al.

\section{Gestational diabetes}

Li et al.

\section{Immunomodulation}

De Smet et al.

CT healthy subjects $(n=14)$. Duration: $4 \mathrm{~h}$

Brull et al.

RCT asthmatic patients $(n=58)$. Duration: $2+8$ weeks

\section{Osteoporosis}

Granado-Lorencio et al. RCT postmenopausal women $(n=38)$. Duration: 4 weeks
Margarine spread with $(n=123)$ or without $(n=121)$ PS

Breakfast wheat biscuit (2 g PS) and standard (2.2

$2.2 \mathrm{~g} /$ day of added PS in $700 \mathrm{ml}$ milk

B-sitosterol (20 mg, which contains a mixture of PS), three times/day or placebo $\beta$-sitosterol (130 mg) and placebo

Plant sterols intake, through food frequency questionnaire

Plant sterols, through food frequency questionnaire

Impact of food diet, via detailed food frequency questionnaire

and a lower cancer risk

Margarine spread with $(n=102)$ or without $(n=104)$ PS

Snake with or without plant stanol esters ( $4 \mathrm{~g} /$ day)

Plant stanol-rich soy-based yogurts

(4 g stanols/day) or control yogurts

$\boldsymbol{\beta}$-cryptoxanthin $(0.75 \mathrm{mg} /$ day) and PS ( $1.5 \mathrm{~g} /$ day), single or combined
LDL-C lowering effect between wholegrain wheat biscuits and plant sterol-enriched wholegrain wheat breakfast cereal biscuit was $0.23 \mathrm{mmo} / \mathrm{L}(5.6 \%, p=0.001)$

PS-enriched milk intake led to a decrease in LDL-C levels in men

Remarkable improvement $(p<0.01)$ in symptoms score and urinary flow parameters, thus revealing the $B$-sitosterol effectiveness

Marked improvements $(p<0.01)$ in symptoms score and quality of life index and an increase in Qmax and a decrease in postvoid residual urinary volume Highest quartile intake of PS led to a 50\% reduction in lung cancer risk (OR 0.29, $95 \% \mathrm{Cl}, 0.14-0.63)$

Highest PS intake was inversely related to gastric cancer risk (OR 0.09, 95\% Cl, 0.02-0.32)

A lower risk was documented for women in the highest quintile of stigmasterol intake (OR $0.42,95 \% \mathrm{Cl}, 0.20-0.87$ )

In PS-rich margarine spread, TAG $(p=0.017)$, TC $(p=0.032)$, and LDL-C $(p=0.027)$ levels were remarkably reduced, while HDL-C $(p=0.041)$ increased compared to baseline; also, fasting plasma glucose $(p=0.021)$ and serum insulin $(p=0.018)$ evels, insulin check index $(p=0.035)$, and $\beta$-cell function $(p=0.029)$ were also remarkably improved

PS-rich margarine spread had benefits on maternal diabetic symptoms, namely, in improving lipid composition (TC, $p=0.03 ; \mathrm{LDL}, p=0.02 ; \mathrm{HDL}, p=0.03$ ) and glucose metabolism $(p=0.03)$, decreasing the incidence of neonatal complications

No changes in genes profiles expression; T-cell function-involved pathways were downregulated in the jejunum

Higher antibody titers against hepatitis A virus (three and four weeks postvaccination, $p=0.037$ and $p=0.030$, respectively) and marked reductions in plasma total lg-E,

L-1 $\beta(p<0.05)$, and TNF- $\alpha(p<0.05)$ levels in treated group

$\boldsymbol{\beta}$-cryptoxanthin combined with PS led to marked changes in TC $(p=0.0047)$, HDL$C(p=0.0057)$, and LDL-C $(p=0.0014)$ levels and bone turnover markers

AST, aspartate aminotransferase; ALT, alanine aminotransferase; CT, clinical trial; CS, cohort study; CCS, case-control study; HDL-C, high-density lipoprotein cholesterol; hs-CRP, high-sensitivity C-reactive protein; IL-6, interleukin 6; LDLc, low-density lipoprotein cholesterol; PSS, phytosterols; RCT, randomized controlled trial; TC, total cholesterol; TAG, triacylglycerol; VLDL-C, very-low-density lipoprotein cholesterol. 
blood and other tissues. For instance, at enterocytes level, it has been shown that PSs are absorbed, at least partially, by a Niemann-Pick 1C Like 1 transporter (NPC1L1)-mediated process (Borel and Desmarchelier, 2018). Thus, genetic variations in other genes, other than ABCG5/G8, may be involved in PS bioavailability modulation. The search for candidate gene associations was only focused on NPC1L1 and apolipoprotein E (APOE). First, it was confirmed that NPC1L1 is the single nucleotide polymorphisms that modulate PS bioavailability (Borel and Desmarchelier, 2018). In two studies, it was observed that, in subjects with apoE $3 / 4$ or $4 / 4$ alleles, the PS bioavailability was higher than in subjects with the apoE $3 / 3$ allele. However, no biological mechanism has been proposed to explain how APOE can modulate PS absorption. This requires further research (Borel and Desmarchelier, 2018). BlancoMorales et al. (Blanco-Morales et al., 2018) studied the action of adding galactooligosaccharides on sterols bioavailability in milk-fruit-based beverages, enriched with three plant sterols, after micellar GI digestion, and found that galactooligosaccharides addition did not affect the overall PS bioavailability.

\section{In Vivo Phytosterol Bioavailability}

Plant sterols are absorbed by many animals, with dogs, pigs, mice, rats, and sheep having approximately 10-20 times more sitosterol in serum and tissues than humans $(\sim 5 \mu \mathrm{M})$ (D'Hollander and Chevallier, 1969; Kuksis et al., 1976; Sugano et al., 1978; Strandberg et al., 1989; Miettinen et al., 1990; Morton et al., 1995; Shahzad et al., 2017).

In spite of structural similarities between cholesterol and PSs, their intake in the intestines of mammals is low. Overall, the PS absorption rates are $0.5 \%, 1.9 \%, 0.04 \%$, and $0.16 \%$ for $\beta$-sitosterol, campesterol, sitostanol, and campestanol, respectively, compared to that of cholesterol (56\%) (Ostlund et al., 2002; Ostlund, 2007). The low PS absorption when compared to cholesterol is attributed to their quick resecretion from intestinal cells back into the GI lumen through ABC G5 and ABC G8 transporters (Berge et al., 2000).

\section{Comparison of Preclinical and Clinical Findings}

Garcia-Llatas et al. (Garcia-Llatas et al., 2015) investigated for the first time preclinical and clinical PS bioavailability. Two fruit beverages based on milk were used; they were enriched with plant sterols and $\beta-\mathrm{Cx}$, and their suitability was compared as phytosterol-rich food matrices and feasible effects on PS absorption (Garcia-Llatas et al., 2015). As main findings, the authors concluded that both in vitro (bioaccessibility determined from simulated gastrointestinal digestion) and in vivo (response in serum from individuals of an interventional study) models give similar results. In 36 postmenopausal women, Garcia-Llatas et al. (2015) stated that serum campesterol concentrations were notably raised (within $0.3-0.4 \mu \mathrm{g} / \mathrm{ml}$ ) one month after beverage intake (1.5 g of PS/ day). Thus, the authors concluded that the duration of PS-rich foods intake may affect serum levels and, consequently, their absorption. In the studies of Garcia-Llatas et al. (2015), Plana et al. (2008), and Casas-Agustench et al. (2012), with a duration of 28-42 days, it was established that the composition of bioavailable PS consumed with food included $\beta$-sitosterol $(\geq$ $70 \%$ ) and campesterol ( $\leq 10 \%$ ). A longer investigation (up to 90 days) suggested that the bioavailability of both PS was equalized. After three months, the authors established lesser contents of $\beta$ sitosterol (37-50\%) and higher contents of campesterol (20-30\%) in the subject's serum (Hernandez-Mijares et al., 2010).

\section{Phytosterol Bioavailability in Humans}

Ostlund et al. (2002) assessed the systemic intake of lecithinemulsified $\Delta^{5}$-PS and phytosterols consumed with food and having isotopic labeling. The absorption of $600 \mathrm{mg}$ of soybean $\Delta^{5}$ sterols added to subject's standard breakfast was $0.512 \pm 0.038 \%$ for sitosterol, $1.89 \pm 0.27 \%$ for campesterol, $0.0441 \pm 0.004 \%$ for sitostanol, and $0.155 \pm 0.017 \%$ for campestanol. The authors also stated that the lack of a double bond in position five of the sterol cycle reduced absorption by more than eightfold. Indeed, the plasma concentration $\left(t^{1 / 2}\right)$ for stanols was achieved faster than that for delta5-sterols. Thus, it was stated that PS absorption proficiency is lower than previously stated. Indeed, both campestanol and sitostanol absorption were solely $\sim 10 \%$ of the absorption of the corresponding $\Delta^{5}$ sterols, which indicates the dominant effect of the double bond saturation on absorption.

Several investigations have tested the serum PS concentrations after consuming PS-rich foods. These low-fat products included dairy products, such as low-fat milk and yogurt or fermented milk. All these studies were published by Ras et al., (2013) in a meta-analysis, including data from 41 studies, with a total of 2084 patients. The average PS dose added to food was $1.6 \mathrm{~g} /$ day (range: 0.3-3.2 g/day). Plasma sitosterol and campesterol concentrations were raised by on average $2.24 \mu \mathrm{mol} / \mathrm{L}(31 \%)$ and $5.00 \mu \mathrm{mol} / \mathrm{L}$ (37\%), respectively, compared to control. The increase in both sitosterol and campesterol concentrations was due to the total PS and baseline doses used and the composition of the tested products. For PS doses of $2.0 \mathrm{~g} /$ day and $3.2 \mathrm{~g} /$ day, the increase for sitosterol and campesterol averaged $3.56 \mu \mathrm{mol} / \mathrm{L}$ and $7.64 \mu \mathrm{mol} / \mathrm{L}$, respectively.

Baseline plasma sitosterol $(6.9 \mu \mathrm{mol} / \mathrm{L})$ and campesterol (13.1 $\mu \mathrm{mol} / \mathrm{L})$ concentrations stated by Ras et al., (2013) were also comparable to that previously published by Chan et al., (2006), who included data from 45 studies, where the average baseline concentrations of sitosterol and campesterol in the general population were $7.9 \mu \mathrm{mol} / \mathrm{L}$ and $14.2 \mu \mathrm{mol} / \mathrm{L}$, respectively. According to Ras et al., (2013), changes in plasma PS concentration were linked to the PS dose daily consumed, and it was also established that the higher the dose, the greater the increase in both sitosterol and campesterol concentrations. The authors also reported that an even greater increase in plasma PS may be at doses $>3.2 \mathrm{~g} /$ day.

Davidson et al. (Davidson et al., 2001) also assessed the PS content in the blood serum when 3,6 , and $9 \mathrm{gPS} /$ day were added to food and found that the increase in serum PSs differed 
slightly between the three doses used. However, even at the highest dose ( $9 \mathrm{~g} /$ day), the total absolute PS doses remained $<2 \mathrm{mg} / \mathrm{dl}(\sim 50 \mu \mathrm{mol} / \mathrm{L})$. Another work showed an increase in PS intake $(1.25,2.5$, and $5 \mathrm{~g} /$ day) along with a minerals' mixture over three consecutive five-week periods (Tuomilehto et al., 2009). Serum sitosterol contents were raised dose-dependently, while campesterol did not. These results do not allow clear conclusions regarding doseresponse relationships for plasma PS at higher doses when consumed with food ( $>3 \mathrm{~g} /$ day). The PS mixture composition and the source type also affected the magnitude of sitosterol and campesterol concentration increase in plasma. In separate studies, plasma PS concentrations were determined at different time points (De Jong et al., 2008), and differences in plasma concentrations of both sterols appeared to stabilize over time. For example, in the study of De Jong et al. (2008), the plasma concentrations of sitosterol and campesterol were the same after 45 and 85 weeks.

Salen et al. (1970) also found that oral PS bioavailability is extremely low $(0.5-5 \%)$, depending on the sterols structure. In their study, $\beta$-sitosterol metabolism was compared with that of cholesterol in 12 patients who consumed $\beta$-sitosterol from a typical American diet. Plasma $\beta$-sitosterol concentration ranged from $0.30 \mathrm{mg} / 100 \mathrm{ml}$ to $1.02 \mathrm{mg} / 100 \mathrm{ml}$, and plasma levels increased only slightly when the intake of $\beta$-sitosterol was significantly increased. With the consumption of food devoid of plant sterols, plasma and feces were quickly released from $\beta$ sitosterol. The concentration of esterified $\beta$-sitosterol in plasma was similar to that of cholesterol. However, the $\beta$-sitosterol esterification rate was lower than that of cholesterol (Salen et al., 1970). Thus, as studied patients do not have an endogenous $\beta$-sitosterol synthesis, the daily $\beta$-sitosterol turnover was equal to its daily intake after a meal. $\beta$-sitosterol absorption was $5 \%$ (or less) of daily intake, while that of cholesterol was $45-54 \%$. Around $20 \%$ of $\beta$-sitosterol absorbed is metabolized to cholic and chenodeoxycholic acid, while the exceeding is excreted in the bile as a free sterol, with its elimination being faster than that of cholesterol (Salen et al., 1970).

Metabolic turnover, absolute oral bioavailability, clearance, and distribution volume of $\beta$-sitosterol were tested by Duchateau et al. in healthy volunteers (Duchateau et al., 2012) using $\left[{ }^{14} \mathrm{C}\right]$ $\beta$-sitosterol as an isotopic indicator at doses ranging from $3 \mu \mathrm{g}$ to $4 \mu \mathrm{g}$, which was low enough as not to disturb diet-derived $\beta$ sitosterol kinetics. The absolute $\beta$-sitosterol bioavailability was extremely low $(0.41 \%)$, with its metabolites not being detected in plasma (Duchateau et al., 2012). Thus, given the generally low PS bioavailability noticed in consumed food, several factors can influence this indicator (Racette et al., 2015) including the following:

(1) PS type (i.e., plant sterol or stanol, esterified against nonesterified, steryl glycosides, and PS solubility). A direct correlation between chemical structure (saturation degree of the sterol ring and side-chain length) and low absorption rate has been stated. Campesterol (with a methyl group) has higher absorption rates than $\beta$-sitosterol (with an ethyl group) (Bradford and Awad, 2007; Miras-Moreno et al., 2016).

(2) Chemical structure of PSs (e.g., sitosterol, campesterol, stigmasterol, brassicasterol, $\Delta$-5-avenasterol, sitostanol, or campestanol).

(3) PS source (e.g., soybean oil, corn oil, or shea nut oil).

(4) Processing (e.g., refining or hydrogenation). Refining and hydrogenation of vegetable oils reduce both the content of free sterols and sterols amount in oils (Phillips et al., 2002; Racette et al., 2015).

(5) Food preparation (e.g., boiling) (Normen et al., 1999; Racette et al., 2015).

(6) Other nutrients (e.g., fiber) and aspects related to the food item (i.e., food matrix, injected dose, administration frequency and time, delivery method (emulsifiers use soy lecithin), and surfactants) (Berger et al., 2004).

(7) Genetic factors (Berger et al., 2004).

\section{CONCLUSIONS}

PSs are plant-derived steroids. Over 250 PSs have been isolated, and each plant species contains a characteristic phytosterol composition. A wide number of researches have reported that PSs possess a wide variety of interesting pharmacological properties, including anti-inflammatory, antioxidant, antidiabetic, chemopreventive, and antiatherosclerotic effects. Nonetheless, PS bioavailability is a limiting aspect that may be affected by multiple factors, such as the type, source, processing, preparation, delivery method, food matrix, dose, time of administration into the body, and genetic factors, and there exists an intercorrelation between low absorption rates and their chemical structure. Thus, further studies are needed to ensure a more in-depth understanding of the multiple potentialities of PSs and to design upcoming strategies to overcome the currently identified bioavailability-related gaps.

\section{AUTHOR CONTRIBUTIONS}

All authors contributed equally to this work. JS-R, WZ, FS, WK, and NCM critically reviewed the manuscript. All the authors read and approved the final manuscript. All authors have read and agreed to the published version of the manuscript.

\section{ACKNOWLEDGMENTS}

NCM acknowledges the Portuguese Foundation for Science and Technology under the Horizon 2020 Program (PTDC/PSI-GER/ 28076/2017). 


\section{REFERENCES}

Abumweis, S. S., Barake, R., and Jones, P. J. (2008). Plant sterols/stanols as cholesterol lowering agents: a meta-analysis of randomized controlled trials. Food Nutr. Res. 52, 1811. doi:10.3402/fnr.v52i0.1811

Aldini, R., Micucci, M., Cevenini, M., Fato, R., Bergamini, C., Nanni, C., et al. (2014). Antiinflammatory effect of phytosterols in experimental murine colitis model: prevention, induction, remission study. PloS One 9, e108112. doi:10. 1371/journal.pone.0108112

Alvarez-Sala, A., Attanzio, A., Tesoriere, L., Garcia-Llatas, G., Barberá, R., and Cilla, A. (2019). Apoptotic effect of a phytosterol-ingredient and its main phytosterol ( $\beta$-sitosterol) in human cancer cell lines. Int. J. Food Sci. Nutr. 70, 323-334. doi:10.1080/09637486.2018.1511689

Alvarez-Sala, A., Garcia-Llatas, G., Cilla, A., Barberá, R., Sánchez-Siles, L. M., and Lagarda, M. J. (2016). Impact of lipid components and emulsifiers on plant sterols bioaccessibility from milk-based fruit beverages. J. Agric. Food Chem. 64, 5686-5691. doi:10.1021/acs.jafc.6b02028

Alvarez-Sala, A., Ávila-Gálvez, M. Á., Cilla, A., Barberá, R., Garcia-Llatas, G., Espín, J. C., et al. (2018a). Physiological concentrations of phytosterols enhance the apoptotic effects of 5-fluorouracil in colon cancer cells. J. Funct. Foods 49, 52-60. doi:10.1016/j.jff.2018.08.016

Alvarez-Sala, A., Blanco-Morales, V., Cilla, A., Garcia-Llatas, G., Sánchez-Siles, L. M., Barberá, R., et al. (2018b). Safe intake of a plant sterol-enriched beverage with milk fat globule membrane: bioaccessibility of sterol oxides during storage. J. Food Compos. Anal. 68, 111-117. doi:10.1016/j.jfca.2017.03.011

Alvarez-Sala, A., Blanco-Morales, V., Cilla, A., Silvestre, R. Á., Hernández-Álvarez, E., Granado-Lorencio, F., et al. (2018c). A positive impact on the serum lipid profile and cytokines after the consumption of a plant sterol-enriched beverage with a milk fat globule membrane: a clinical study. Food Funct. 9, 5209-5219. doi:10.1039/c8fo00353j

Alvarez-Sala, A., López-García, G., Attanzio, A., Tesoriere, L., Cilla, A., Barberá, R., et al. (2018d). Effects of plant sterols or $\beta$-cryptoxanthin at physiological serum concentrations on suicidal erythrocyte death. J. Agric. Food Chem. 66, 1157-1166. doi:10.1021/acs.jafc.7b05575

Assmann, G., Cullen, P., Erbey, J., Ramey, D. R., Kannenberg, F., and Schulte, H. (2006). Plasma sitosterol elevations are associated with an increased incidence of coronary events in men: results of a nested case-control analysis of the Prospective Cardiovascular Münster (PROCAM) study. Nutr. Metabol. Cardiovasc. Dis. 16, 13-21. doi:10.1016/j.numecd.2005.04.001

Awad, A. B., Chinnam, M., Fink, C. S., and Bradford, P. G. (2007). beta-Sitosterol activates Fas signaling in human breast cancer cells. Phytomedicine 14, 747-754. doi:10.1016/j.phymed.2007.01.003

Awad, A. B., Downie, A., Fink, C. S., and Kim, U. (2000). Dietary phytosterol inhibits the growth and metastasis of MDA-MB-231 human breast cancer cells grown in SCID mice. Anticancer Res. 20, 821-824.

Baldi, A., and Pinotti, L. (2008). Lipophilic microconstituents of milk. New York, NY: Springer.

Baskar, A. A., Ignacimuthu, S., Paulraj, G. M., and Al Numair, K. S. (2010). Chemopreventive potential of beta-Sitosterol in experimental colon cancer model--an in vitro and in vivo study. BMC Compl. Alternative Med. 10, 24. doi:10.1186/1472-6882-10-24

Becker, M., Staab, D., and Von Bergmann, K. (1993). Treatment of severe familial hypercholesterolemia in childhood with sitosterol and sitostanol. J. Pediatr. 122, 292-296. doi:10.1016/s0022-3476(06)80136-8

Berge, K. E., Tian, H., Graf, G. A., Yu, L., Grishin, N. V., Schultz, J., et al. (2000). Accumulation of dietary cholesterol in sitosterolemia caused by mutations in adjacent ABC transporters. Science 290, 1771-1775. doi:10.1126/science.290. 5497.1771

Berger, A., Jones, P. J., and Abumweis, S. S. (2004). Plant sterols: factors affecting their efficacy and safety as functional food ingredients. Lipids Health Dis. 3, 5. doi:10.1186/1476-511X-3-5

Berges, R. R., Windeler, J., Trampisch, H. J., Senge, T., and B-Sitosterol Study, G. (1995). Randomised, placebo-controlled, double-blind clinical trial of betasitosterol in patients with benign prostatic hyperplasia. Beta-sitosterol study group. Lancet 345, 1529-1532. doi:10.1016/s0140-6736(95)91085-9

Blanco-Morales, V., López-García, G., Cilla, A., Garcia-Llatas, G., Barberá, R., Lagarda, M. J., et al. (2018). The impact of galactooligosaccharides on the bioaccessibility of sterols in a plant sterol-enriched beverage: adaptation of the harmonized INFOGEST digestion method. Food Funct. 9, 2080-2089. doi:10. 1039/c8fo00155c

Bohn, T., Tian, Q., Chitchumroonchokchai, C., Failla, M. L., Schwartz, S. J., Cotter, R., et al. (2007). Supplementation of test meals with fat-free phytosterol products can reduce cholesterol micellization during simulated digestion and cholesterol accumulation by Caco-2 cells. J. Agric. Food Chem. 55, 267-272. doi:10.1021/jf0618291

Borel, P., and Desmarchelier, C. (2018). Bioavailability of fat-soluble vitamins and phytochemicals in humans: effects of genetic variation. Annu. Rev. Nutr. 38, 69-96. doi:10.1146/annurev-nutr-082117-051628

Bouic, P. J. (2001). The role of phytosterols and phytosterols in immune modulation: a review of the past 10 years. Curr. Opin. Clin. Nutr. Metab. Care 4, 471-475. doi:10.1097/00075197-200111000-00001

Bradford, P. G., and Awad, A. B. (2007). Phytosterols as anticancer compounds. Mol. Nutr. Food Res. 51, 161-170. doi:10.1002/mnfr.200600164

Brown, A. W., Hang, J., Dussault, P. H., and Carr, T. P. (2010). Phytosterol ester constituents affect micellar cholesterol solubility in model bile. Lipids 45, 855-862. doi:10.1007/s11745-010-3456-6

Brufau, G., Canela, M. A., and Rafecas, M. (2007). Phytosterols, but not pectin, added to a high-saturated-fat diet modify saturated fatty acid excretion in relation to chain length. J. Nutr. Biochem. 18, 580-586. doi:10.1016/j.jnutbio. 2006.10.003

Brüll, F., De Smet, E., Mensink, R. P., Vreugdenhil, A., Kerksiek, A., Lütjohann, D., et al. (2016). Dietary plant stanol ester consumption improves immune function in asthma patients: results of a randomized, double-blind clinical trial. Am. J. Clin. Nutr. 103, 444-453. doi:10.3945/ajcn.115.117531

Brüll, F., and Mensink, R. (2009). Plant sterols: functional lipids in immune function and inflammation?. Clin. Lipidol. 4, 355-365. doi:10.2217/clp.09.26

Cabral, C. E., and Klein, M. R. S. T. (2017). Phytosterols in the treatment of hypercholesterolemia and prevention of cardiovascular diseases. Arq. Bras. Cardiol. 109, 475-482. doi:10.5935/abc.20170158

Calpe-Berdiel, L., Escolà-Gil, J. C., Benítez, S., Bancells, C., González-Sastre, F., Palomer, X., et al. (2007). Dietary phytosterols modulate T-helper immune response but do not induce apparent anti-inflammatory effects in a mouse model of acute, aseptic inflammation. Life Sci. 80, 1951-1956. doi:10.1016/j.lfs. 2007.02.032

Casas-Agustench, P., Serra, M., Pérez-Heras, A., Cofán, M., Pintó, X., Trautwein, E. A., et al. (2012). Effects of plant sterol esters in skimmed milk and vegetable-fatenriched milk on serum lipids and non-cholesterol sterols in hypercholesterolaemic subjects: a randomised, placebo-controlled, crossover study. Br. J. Nutr. 107, 1766-1775. doi:10.1017/S0007114511005162

Chan, Y. M., Varady, K. A., Lin, Y., Trautwein, E., Mensink, R. P., Plat, J., et al. (2006). Plasma concentrations of plant sterols: physiology and relationship with coronary heart disease. Nutr. Rev. 64, 385-402. doi:10.1111/j.1753-4887.2006. tb00224.x

Chen, Q., Gruber, H., Swist, E., Coville, K., Pakenham, C., Ratnayake, W. M., et al. (2010). Dietary phytosterols and phytosterols decrease cholesterol levels but increase blood pressure in WKY inbred rats in the absence of salt-loading. Nutr. Metab. 7, 11. doi:10.1186/1743-7075-7-11

Cheung, C. L., Ho, D. K., Sing, C. W., Tsoi, M. F., Cheng, V. K., Lee, G. K., et al. (2017). Randomized controlled trial of the effect of phytosterols-enriched low-fat milk on lipid profile in Chinese. Sci. Rep. 7, 41084. doi:10.1038/ srep41084

Cicero, A. F. G., Fogacci, F., Rosticci, M., Parini, A., Giovannini, M., Veronesi, M., et al. (2017). Effect of a short-term dietary supplementation with phytosterols, red yeast rice or both on lipid pattern in moderately hypercholesterolemic subjects: a three-arm, double-blind, randomized clinical trial. Nutr. Metab. 14, 61. doi:10.1186/s12986-017-0214-2

Cilla, A., Attanzio, A., Barberá, R., Tesoriere, L., and Livrea, M. A. (2015). Antiproliferative effect of main dietary phytosterols and $\beta$-cryptoxanthin alone or combined in human colon cancer Caco- 2 cells through cytosolic $\mathrm{Ca}+2-$ and oxidative stress-induced apoptosis. J. Funct. Foods 12, 282-293. doi:10.1016/j. jff.2014.12.001

Clifton, P., and Keogh, J. (2018). Cholesterol-lowering effects of plant sterols in one serve of wholegrain wheat breakfast cereal biscuits-a randomised crossover clinical trial. Foods 7, 39. doi:10.3390/foods7030039

Cuevas-Tena, M., Gómez Del Pulgar, E. M., Benítez-Páez, A., Sanz, Y., Alegría, A., and Lagarda, M. J. (2018). Plant sterols and human gut microbiota relationship: 
an in vitro colonic fermentation study. J. Funct. Foods 44, 322-329. doi:10.1016/ j.jff. 2018.03 .023

D'Hollander, F., and Chevallier, F. (1969). [Qualitative and quantitative estimation of free and esterified sterols in whole rat and in 23 of its tissues and organs]. Biochim. Biophys. Acta 176, 146-162.

Daniel, P. T., Wieder, T., Sturm, I., and Schulze-Osthoff, K. (2001). The kiss of death: promises and failures of death receptors and ligands in cancer therapy. Leukemia 15, 1022-1032. doi:10.1038/sj.leu.2402169

Davidson, M. H., Maki, K. C., Umporowicz, D. M., Ingram, K. A., Dicklin, M. R., Schaefer, E., et al. (2001). Safety and tolerability of esterified phytosterols administered in reduced-fat spread and salad dressing to healthy adult men and women. J. Am. Coll. Nutr. 20, 307-319. doi:10.1080/07315724.2001.10719051

De Jong, A., Plat, J., Lütjohann, D., and Mensink, R. P. (2008). Effects of long-term plant sterol or stanol ester consumption on lipid and lipoprotein metabolism in subjects on statin treatment. Br. J. Nutr. 100, 937-941. doi:10.1017/ s0007114508966113

De Jongh, S., Vissers, M. N., Rol, P., Bakker, H. D., Kastelein, J. J., and Stroes, E. S. (2003). Plant sterols lower LDL cholesterol without improving endothelial function in prepubertal children with familial hypercholesterolaemia. J. Inherit. Metab. Dis. 26, 343-351. doi:10.1023/a:1025155002348

De Smet, E., Mensink, R. P., Boekschoten, M. V., De Ridder, R., Germeraad, W. T., Wolfs, T. G., et al. (2015). An acute intake of plant stanol esters alters immunerelated pathways in the jejunum of healthy volunteers. Br. J. Nutr. 113, 794-802. doi:10.1017/S000711451400350X

De Stefani, E., Boffetta, P., Ronco, A. L., Brennan, P., Deneo-Pellegrini, H., Carzoglio, J. C., et al. (2000). Plant sterols and risk of stomach cancer: a case-control study in Uruguay. Nutr. Canc. 37, 140-144. doi:10.1207/ S15327914NC372_4

Denke, M. A. (1995). Lack of efficacy of low-dose sitostanol therapy as an adjunct to a cholesterol-lowering diet in men with moderate hypercholesterolemia. Am. J. Clin. Nutr. 61, 392-396. doi:10.1093/ajen/61.2.392

Dietschy, J. M., and Turley, S. D. (2002). Control of cholesterol turnover in the mouse. J. Biol. Chem. 277, 3801-3804. doi:10.1074/jbc.R100057200

Duchateau, G., Cochrane, B., Windebank, S., Herudzinska, J., Sanghera, D., Burian, A., et al. (2012). Absolute oral bioavailability and metabolic turnover of $\beta$-sitosterol in healthy subjects. Drug Metab. Dispos. 40, 2026-2030. doi:10. $1124 / \mathrm{dmd} .112 .046623$

Dutta, P. C. (2003). Phytosterols as functional food components and nutraceuticals. Boca Raton, FL: CRC Press.

Escurriol, V., Cofán, M., Moreno-Iribas, C., Larrañaga, N., Martínez, C., Navarro, C., et al. (2010). Phytosterol plasma concentrations and coronary heart disease in the prospective Spanish EPIC cohort. J. Lipid Res. 51, 618-624. doi:10.1194/ jlr.P000471

Fassbender, K., Lütjohann, D., Dik, M. G., Bremmer, M., König, J., Walter, S., et al. (2008). Moderately elevated plant sterol levels are associated with reduced cardiovascular risk--the LASA study. Atherosclerosis 196, 283-288. doi:10.1016/ j.atherosclerosis.2006.10.032

Ferguson, J. J. A., Stojanovski, E., Macdonald-Wicks, L., and Garg, M. L. (2018). Curcumin potentiates cholesterol-lowering effects of phytosterols in hypercholesterolaemic individuals. A randomised controlled trial. Metabolism 82, 22-35. doi:10.1016/j.metabol.2017.12.009

Floros, J. D., Newsome, R., Fisher, W., Barbosa-Cánovas, G. V., Chen, H., Dunne, C. P., et al. (2010). Feeding the world today and tomorrow: the importance of food science and technology. Compr. Rev. Food Sci. Food Saf. 9, 572-599. doi:10. $1111 / j .1541-4337.2010 .00127 . x$

Gabay, O., Sanchez, C., Salvat, C., Chevy, F., Breton, M., Nourissat, G., et al. (2010). Stigmasterol: a phytosterol with potential anti-osteoarthritic properties. Osteoarthritis Cartilage 18, 106-116. doi:10.1016/j.joca.2009.08.019

Gao, F., Wang, G., Wang, L., and Guo, N. (2017). Phytosterol nutritional supplement improves pregnancy and neonatal complications of gestational diabetes mellitus in a double-blind and placebo-controlled clinical study. Food Funct 8, 424-428. doi:10.1039/c6fo01777k

Garcia-Llatas, G., Cilla, A., Alegría, A., and Lagarda, M. J. (2015). Bioavailability of plant sterol-enriched milk-based fruit beverages: in vivo and in vitro studies. J. Funct. Foods 14, 44-50. doi:10.1016/j.jff.2015.01.023

Granado-Lorencio, F., Lagarda, M. J., Garcia-López, F. J., Sánchez-Siles, L. M., Blanco-Navarro, I., Alegría, A., et al. (2014). Effect of $\beta$-cryptoxanthin plus phytosterols on cardiovascular risk and bone turnover markers in post-menopausal women: a randomized crossover trial. Nutr. Metabol. Cardiovasc. Dis. 24, 1090-1096. doi:10.1016/j.numecd.2014.04.013

Gupta, A. K., Savopoulos, C. G., Ahuja, J., and Hatzitolios, A. I. (2011). Role of phytosterols in lipid-lowering: current perspectives. QJM 104, 301-308. doi:10. 1093/qjmed/hcr007

Heinemann, T., Leiss, O., and Von Bergmann, K. (1986). Effect of low-dose sitostanol on serum cholesterol in patients with hypercholesterolemia. Atherosclerosis 61, 219-223. doi:10.1016/0021-9150(86)90141-3

Herbst, R. S., Eckhardt, S. G., Kurzrock, R., Ebbinghaus, S., O'dwyer, P. J., Gordon, M. S., et al. (2010). Phase I dose-escalation study of recombinant human Apo2L/TRAIL, a dual proapoptotic receptor agonist, in patients with advanced cancer. J. Clin. Oncol. 28, 2839-2846. doi:10.1200/JCO.2009.25.1991

Hernández-Mijares, A., Bañuls, C., Rocha, M., Morillas, C., Martínez-Triguero, M. L., Víctor, V. M., et al. (2010). Effects of phytosterol ester-enriched low-fat milk on serum lipoprotein profile in mildly hypercholesterolaemic patients are not related to dietary cholesterol or saturated fat intake. Br. J. Nutr. 104, 1018-1025. doi:10.1017/S0007114510001686

Hwang, S. L., Kim, H. N., Jung, H. H., Kim, J. E., Choi, D. K., Hur, J. M., et al. (2008). Beneficial effects of beta-sitosterol on glucose and lipid metabolism in L6 myotube cells are mediated by AMP-activated protein kinase. Biochem. Biophys. Res. Commun. 377, 1253-1258. doi:10.1016/j.bbrc.2008.10.136

Iaccarino, N., Amato, J., Pagano, B., Di Porzio, A., Micucci, M., Bolelli, L., et al. (2019). Impact of phytosterols on liver and distal colon metabolome in experimental murine colitis model: an explorative study. J. Enzym. Inhib. Med. Chem. 34, 1041-1050. doi:10.1080/14756366.2019.1611802

Ikeda, I., and Sugano, M. (1978). Comparison of absorption and metabolism of beta-sitosterol and beta-sitostanol in rats. Atherosclerosis 30, 227-237. doi:10. 1016/0021-9150(78)90049-7

Ikeda, I., Tanaka, K., Sugano, M., Vahouny, G. V., and Gallo, L. L. (1988). Inhibition of cholesterol absorption in rats by plant sterols. J. Lipid Res. 29, $1573-1582$.

Imran, M., Salehi, B., Sharifi-Rad, J., Gondal, T. A., Saeed, F., Imran, A., et al. (2019). Kaempferol: a key emphasis to its anticancer potential. Molecules 24, 2277. doi:10.3390/molecules 24122277

Jakulj, L., Vissers, M. N., Rodenburg, J., Wiegman, A., Trip, M. D., and Kastelein, J. J. (2006). Plant stanols do not restore endothelial function in pre-pubertal children with familial hypercholesterolemia despite reduction of low-density lipoprotein cholesterol levels. J. Pediatr. 148, 495-500. doi:10.1016/j.jpeds.2005. 11.023

Javanmardi, M. A., Mohammad Shahi, M., Seyedian, S. S., and Haghighizadeh, M. H. (2018). Effects of phytosterol supplementation on serum levels of lipid profiles, liver enzymes, inflammatory markers, adiponectin, and leptin in patients affected by nonalcoholic fatty liver disease: a double-blind, placebocontrolled, randomized clinical trial. J. Am. Coll. Nutr. 1-8 [Epub ahead of print]. doi:10.1080/07315724.2018.1466739

Jessup, W., Herman, A., and Chapman, J. (2008). Phytosterols in cardiovascular disease:innocuous dietary components,or accelerators of atherosclerosis? Future Lipidol. 3, 301-310. doi:10.2217/17460875.3.3.301

Jiang, L., Zhao, X., Xu, J., Li, C., Yu, Y., Wang, W., et al. (2019). The protective effect of dietary phytosterols on cancer risk: a systematic meta-analysis. J Oncol 2019, 7479518. doi:10.1155/2019/7479518

Jones, P. J., and Abumweis, S. S. (2009). Phytosterols as functional food ingredients: linkages to cardiovascular disease and cancer. Curr. Opin. Clin. Nutr. Metab. Care 12, 147-151. doi:10.1097/mco.0b013e328326770f

Jones, P. J., Vanstone, C. A., Raeini-Sarjaz, M., and St-Onge, M. P. (2003). Phytosterols in low- and nonfat beverages as part of a controlled diet fail to lower plasma lipid levels. J. Lipid Res. 44, 1713-1719. doi:10.1194/jlr.M300089-JLR200

Katan, M. B., Grundy, S. M., Jones, P., Law, M., Miettinen, T., Paoletti, R., et al. (2003). Efficacy and safety of plant stanols and sterols in the management of blood cholesterol levels. Mayo Clin. Proc. 78, 965-978. doi:10.4065/78.8.965

Ketomaki, A., Gylling, H., and Miettinen, T. A. (2004). Effects of plant stanol and sterol esters on serum phytosterols in a family with familial hypercholesterolemia including a homozygous subject. J. Lab. Clin. Med. 143, 255-262. doi:10.1016/j.lab.2003.11.007

Klippel, K. F., Hiltl, D. M., and Schipp, B. (1997). A multicentric, placebocontrolled, double-blind clinical trial of beta-sitosterol (phytosterol) for the treatment of benign prostatic hyperplasia. German BPH-Phyto Study group. Br. J. Urol. $80,427-432$ 
Konno, R., Kaneko, Y., Suzuki, K., and Matsui, Y. (2005). Effect of 5-Campestenone (24-methylcholest-5-en-3-one) on Zucker diabetic fatty rats as a type 2 diabetes mellitus model. Horm. Metab. Res. 37, 79-83. doi:10.1055/s-2005-861171

Kuksis, A., Marai, L., Myher, J. J., and Geher, K. (1976). Identification of plant sterols in plasma and red blood cells of man and experimental animals. Lipids 11, 581-586. doi:10.1007/BF02532869

Lees, A. M., Mok, H. Y., Lees, R. S., Mccluskey, M. A., and Grundy, S. M. (1977). Plant sterols as cholesterol-lowering agents: clinical trials in patients with hypercholesterolemia and studies of sterol balance. Atherosclerosis 28, 325-338. doi:10.1016/0021-9150(77)90180-0

Li, Q., and Xing, B. (2016). A phytosterol-enriched spread improves lipid profile and insulin resistance of women with gestational diabetes mellitus: a randomized, placebo-controlled double-blind clinical trial. Diabetes Technol. Therapeut. 18, 499-504. doi:10.1089/dia.2016.0103

Lin, X., Racette, S. B., Lefevre, M., Ma, L., Spearie, C. A., Steger-May, K., et al. (2011). Combined effects of ezetimibe and phytosterols on cholesterol metabolism: a randomized, controlled feeding study in humans. Circulation 124, 596-601. doi:10.1161/CIRCULATIONAHA.110.006692

Ling, W. H., and Jones, P. J. (1995). Dietary phytosterols: a review of metabolism, benefits and side effects. Life Sci. 57, 195-206. doi:10.1016/0024-3205(95)00263-6

Llaverias, G., Escolà-Gil, J. C., Lerma, E., Julve, J., Pons, C., Cabré, A., et al. (2013). Phytosterols inhibit the tumor growth and lipoprotein oxidizability induced by a high-fat diet in mice with inherited breast cancer. J. Nutr. Biochem. 24, 39-48. doi:10.1016/j.jnutbio.2012.01.007

López-García, G., Cilla, A., Barberá, R., and Alegría, A. (2017). Antiproliferative effect of plant sterols at colonic concentrations on Caco-2 cells. J. Funct. Foods 39, 84-90. doi:10.1016/j.jff.2017.10.006

López-García, G., Cilla, A., Barberá, R., and Alegría, A. (2020). Anti-inflammatory and cytoprotective effect of plant sterol and galactooligosaccharides-enriched beverages in caco-2 cells. J. Agric. Food Chem. 68, 1862-1870. doi:10.1021/acs.jafc.9b03025

López-García, G., Cilla, A., Barberá, R., Alegría, A., and Recio, M. C. (2019). Effect of a milk-based fruit beverage enriched with plant sterols and/or galactooligosaccharides in a murine chronic colitis model. Foods 8, 114. doi:10.3390/foods8040114

Malini, T., and Vanithakumari, G. (1990). Rat toxicity studies with beta-sitosterol. J. Ethnopharmacol. 28, 221-234. doi:10.1016/0378-8741(90)90032-o

Malinowski, J. M., and Gehret, M. M. (2010). Phytosterols for dyslipidemia. Am. J. Health Syst. Pharm. 67, 1165-1173. doi:10.2146/ajhp090427

Mccann, S. E., Freudenheim, J. L., Marshall, J. R., and Graham, S. (2003). Risk of human ovarian cancer is related to dietary intake of selected nutrients, phytochemicals and food groups. J. Nutr. 133, 1937-1942. doi:10.1093/jn/133.6.1937

Mellies, M., Glueck, C. J., Sweeney, C., Fallat, R. W., Tsang, R. C., and Ishikawa, T. T. (1976). Plasma and dietary phytosterols in children. Pediatrics 57, 60-67.

Mendilaharsu, M., De Stefani, E., Deneo-Pellegrini, H., Carzoglio, J., and Ronco, A. (1998). Phytosterols and risk of lung cancer: a case-control study in Uruguay. Lung Canc. 21, 37-45. doi:10.1016/s0169-5002(98)00044-0

Miettinen, T. A., Puska, P., Gylling, H., Vanhanen, H., and Vartiainen, E. (1995). Reduction of serum cholesterol with sitostanol-ester margarine in a mildly hypercholesterolemic population. N. Engl. J. Med. 333, 1308-1312. doi:10.1056/ NEJM199511163332002

Miettinen, T. A., Tilvis, R. S., and Kesäniemi, Y. A. (1990). Serum plant sterols and cholesterol precursors reflect cholesterol absorption and synthesis in volunteers of a randomly selected male population. Am. J. Epidemiol. 131, 20-31. doi:10. 1093/oxfordjournals.aje.a115479

Miras-Moreno, B., Sabater-Jara, A. B., Pedreño, M. A., and Almagro, L. (2016). Bioactivity of phytosterols and their production in plant in Vitro cultures. J. Agric. Food Chem. 64, 7049-7058. doi:10.1021/acs.jafc.6b02345

Moghadasian, M. H. (2000). Pharmacological properties of plant sterols in vivo and in vitro observations. Life Sci. 67, 605-615. doi:10.1016/s0024-3205(00)00665-2

Morton, G. M., Lee, S. M., Buss, D. H., and Lawrance, P. (1995). Intakes and major dietary sources of cholesterol and phytosterols in the British diet. J. Hum. Nutr. Diet. 8, 429-440. doi:10.1111/j.1365-277X.1995.tb00338.x

Nashed, B., Yeganeh, B., Hayglass, K. T., and Moghadasian, M. H. (2005). Antiatherogenic effects of dietary plant sterols are associated with inhibition of proinflammatory cytokine production in Apo E-KO mice. J. Nutr. 135, 2438-2444. doi:10.1093/jn/135.10.2438

Nik, A. M., Corredig, M., and Wright, A. J. (2011). Release of lipophilic molecules during in vitro digestion of soy protein-stabilized emulsions. Mol. Nutr. Food Res. 55 (Suppl. 2), S278-S289. doi:10.1002/mnfr.201000572
Normén, A. L., Brants, H. A., Voorrips, L. E., Andersson, H. A., Van Den Brandt, P. A., and Goldbohm, R. A. (2001). Plant sterol intakes and colorectal cancer risk in The The Netherlands cohort study on diet and cancer. Am. J. Clin. Nutr. 74, 141-148. doi:10.1093/ajcn/74.1.141

Normén, L., Johnsson, M., Andersson, H., Van Gameren, Y., and Dutta, P. (1999). Plant sterols in vegetables and fruits commonly consumed in Sweden. Eur. J. Nutr. 38, 84-89. doi:10.1007/s003940050048

O'neill, F. H., Sanders, T. A., and Thompson, G. R. (2005). Comparison of efficacy of plant stanol ester and sterol ester: short-term and longer-term studies. Am. J. Cardiol. 96, 29D-36D. doi:10.1016/j.amjcard.2005.03.017

Ogbe, R. J., Ochalefu, D. O., Mafulul, S. G., and Olaniru, O. B. (2015). A review on dietary phytosterols: their occurrence, metabolism and health benefits. Asian J. Plant Sci. Res. 5, 10-21.

Ostlund, R. E., Jr., Mcgill, J. B., Zeng, C. M., Covey, D. F., Stearns, J., Stenson, W. F., and Spilburg, C. A. (2002). Gastrointestinal absorption and plasma kinetics of soy Delta(5)-phytosterols and phytosterols in humans. Am. J. Physiol. Endocrinol. Metab. 282, E911-E916. doi:10.1152/ajpendo.00328.2001

Ostlund, R. E., Jr. (2007). Phytosterols, cholesterol absorption and healthy diets. Lipids 42, 41-45. doi:10.1007/s11745-006-3001-9

Ottestad, I., Ose, L., Wennersberg, M. H., Granlund, L., Kirkhus, B., and Retterstøl, K. (2013). Phytosterol capsules and serum cholesterol in hypercholesterolemia: a randomized controlled trial. Atherosclerosis 228, 421-425. doi:10.1016/j. atherosclerosis.2013.03.001

Pan, X., Zhang, Y., Wang, L., and Hussain, M. M. (2010). Diurnal regulation of MTP and plasma triglyceride by CLOCK is mediated by SHP. Cell Metabol. 12, 174-186. doi:10.1016/j.cmet.2010.05.014

Párraga-Martínez, I., López-Torres-Hidalgo, J. D., Del Campo-Del Campo, J. M., Galdón-Blesa, M. P., Precioso-Yáñez, J. C., Rabanales-Sotos, J., et al. (2015). Long-term effects of plant stanols on the lipid profile of patients with hypercholesterolemia. A randomized clinical trial. Rev. Esp. Cardiol. 68, 665-671. doi:10.1016/j.rec.2014.07.035

Patel, M. D., and Thompson, P. D. (2006). Phytosterols and vascular disease. Atherosclerosis 186, 12-19. doi:10.1016/j.atherosclerosis.2005.10.026

Phillips, K. M., Ruggio, D. M., Toivo, J. I., Swank, M. A., and Simpkins, A. H. (2002). Free and esterified sterol composition of edible oils and fats. J. Food Compos. Anal. 15, 123-142. doi:10.1006/jfca.2001.1044

Piironen, V., Lindsay, D. G., Miettinen, T., Toivo, J., and Lampi, A. M. (2000). Plant sterols: biosynthesis, biological function and their importance to human nutrition. J. Sci. Food Agric. 80, 939-966. doi:10.1002/(SICI)10970010(20000515)80:7<939::AID-JSFA644>3.0.CO;2-3

Piironen, V., Toivo, J., Puupponen-Pimiä, R., and Lampi, A. (2003). Plant sterols in vegetables, fruits and berries. J. Sci. Food Agric. 83, 330-337. doi:10.1002/jsfa. 1316

Pinderski, L. J., Fischbein, M. P., Subbanagounder, G., Fishbein, M. C., Kubo, N., Cheroutre, H., et al. (2002). Overexpression of interleukin-10 by activated $\mathrm{T}$ lymphocytes inhibits atherosclerosis in LDL receptor-deficient Mice by altering lymphocyte and macrophage phenotypes. Circ. Res. 90, 1064-1071. doi:10. 1161/01.res.0000018941.10726.fa

Plana, N., Nicolle, C., Ferre, R., Camps, J., Cos, R., Villoria, J., and Masana, L. (2008). Plant sterol-enriched fermented milk enhances the attainment of LDLcholesterol goal in hypercholesterolemic subjects. Eur. J. Nutr. 47, 32-39. doi:10.1007/s00394-007-0693-4

Plat, J., Baumgartner, S., Vanmierlo, T., Lütjohann, D., Calkins, K. L., Burrin, D. G., et al. (2019). Plant-based sterols and stanols in health \& disease: "Consequences of human development in a plant-based environment?". Prog. Lipid Res. 74, 87-102. doi:10.1016/j.plipres.2019.02.003

Plat, J., Brufau, G., Dallinga-Thie, G. M., Dasselaar, M., and Mensink, R. P. (2009). A plant stanol yogurt drink alone or combined with a low-dose statin lowers serum triacylglycerol and non-HDL cholesterol in metabolic syndrome patients. J. Nutr. 139, 1143-1149. doi:10.3945/jn.108.103481

Poudel, A., Gachumi, G., Wasan, K. M., Dallal Bashi, Z., El-Aneed, A., and Badea, I. (2019). Development and characterization of liposomal formulations containing phytosterols extracted from canola oil deodorizer distillate along with tocopherols as food additives. Pharmaceutics 11, 185. doi:10.3390/ pharmaceutics11040185

Racette, S. B., Lin, X., Lefevre, M., Spearie, C. A., Most, M. M., Ma, L., et al. (2010). Dose effects of dietary phytosterols on cholesterol metabolism: a controlled feeding study. Am. J. Clin. Nutr. 91, 32-38. doi:10.3945/ajcn.2009.28070 
Racette, S. B., Lin, X., Ma, L., and Ostlund, R. E., Jr. (2015). Natural dietary phytosterols. J. AOAC Int. 98, 679-684. doi:10.5740/jaoacint.SGERacette

Rajavel, T., Mohankumar, R., Archunan, G., Ruckmani, K., and Devi, K. P. (2017). Beta sitosterol and Daucosterol (phytosterols identified in Grewia tiliaefolia) perturbs cell cycle and induces apoptotic cell death in A549 cells. Sci. Rep. 7, 3418. doi:10.1038/s41598-017-03511-4

Ras, R. T., Hiemstra, H., Lin, Y., Vermeer, M. A., Duchateau, G. S., and Trautwein, E. A. (2013). Consumption of plant sterol-enriched foods and effects on plasma plant sterol concentrations--a meta-analysis of randomized controlled studies. Atherosclerosis 230, 336-346. doi:10.1016/j.atherosclerosis.2013.08.012

Rideout, T. C., Marinangeli, C. P., and Harding, S. V. (2015a). Triglyceridelowering response to plant sterol and stanol consumption. J. AOAC Int. 98, 707-715. doi:10.5740/jaoacint.SGERideout

Rideout, T. C., Movsesian, C., Tsai, Y. T., Iqbal, A., Raslawsky, A., and Patel, M. S. (2015b). Maternal phytosterol supplementation during pregnancy and lactation modulates lipid and lipoprotein response in offspring of apoE-deficient mice. J. Nutr. 145, 1728-1734. doi:10.3945/jn.115.215061

Rideout, T. C., Ramprasath, V., Griffin, J. D., Browne, R. W., Harding, S. V., and Jones, P. J. (2014). Phytosterols protect against diet-induced hypertriglyceridemia in Syrian golden hamsters. Lipids Health Dis. 13, 5. doi:10.1186/1476-511X-13-5

Rubis, B., Paszel, A., Kaczmarek, M., Rudzinska, M., Jelen, H., and Rybczynska, M. (2008). Beneficial or harmful influence of phytosterols on human cells?. Br. J. Nutr. 100, 1183-1191. doi:10.1017/S0007114508981423

Rui, X., Wenfang, L., Jing, C., Meng, C., Chengcheng, D., Jiqu, X., et al. (2017). Neuroprotective effects of phytosterol esters against high cholesterolinduced cognitive deficits in aged rat. Food Funct 8, 1323-1332. doi:10. 1039/c6fo01656a

Ryökkynen, A., Käyhkö, U. R., Mustonen, A. M., Kukkonen, J. V., and Nieminen, P. (2005). Multigenerational exposure to phytosterols in the mouse. Reprod. Toxicol. 19, 535-540. doi:10.1016/j.reprotox.2004.09.003

Salehi, B., Martorell, M., Arbiser, J. L., Sureda, A., Martins, N., Maurya, P K., et al. (2018). Antioxidants: Positive or Negative Actors?. Biomolecules. 8, 124. doi:10. 3390/biom8040124

Salen, G., Ahrens, E. H., Jr., and Grundy, S. M. (1970). Metabolism of betasitosterol in man. J. Clin. Invest. 49, 952-967. doi:10.1172/JCI106315

Salen, G., Starc, T., Sisk, C. M., and Patel, S. B. (2006). Intestinal cholesterol absorption inhibitor ezetimibe added to cholestyramine for sitosterolemia and xanthomatosis. Gastroenterology 130, 1853-1857. doi:10.1053/j.gastro.2006.02.027

San Mauro-Martín, I., Blumenfeld-Olivares, J. A., Garicano-Vilar, E., Cuadrado, M. Á., Ciudad-Cabañas, M. J., and Collado-Yurrita, L. (2018). Differences in the effect of plant sterols on lipid metabolism in men and women. Top. Clin. Nutr. 33, 31-40. doi:10.1097/TIN.0000000000000123

Schepers, M., Martens, N., Tiane, A., Vanbrabant, K., Liu, H. B., Lütjohann, D., et al. (2020). Edible seaweed-derived constituents: an undisclosed source of neuroprotective compounds. Neural Regen Res 15, 790-795. doi:10.4103/1673-5374.268894

Schiepers, O. J., De Groot, R. H., Van Boxtel, M. P., Jolles, J., De Jong, A., Lütjohann, D., et al. (2009). Consuming functional foods enriched with plant sterol or stanol esters for 85 weeks does not affect neurocognitive functioning or mood in statin-treated hypercholesterolemic individuals. J. Nutr. 139, 1368-1373. doi:10.3945/jn.108.103721

Schonewille, M., Brufau, G., Shiri-Sverdlov, R., Groen, A. K., and Plat, J. (2014). Serum TG-lowering properties of plant sterols and stanols are associated with decreased hepatic VLDL secretion. J. Lipid Res. 55, 2554-2561. doi:10.1194/jlr.M052407

Shahzad, N., Khan, W., Md, S., Ali, A., Saluja, S. S., Sharma, S., et al. (2017). Phytosterols as a natural anticancer agent: current status and future perspective. Biomed. Pharmacother. 88, 786-794. doi:10.1016/j.biopha.2017.01.068

Shao, A., Drewnowski, A., Willcox, D. C., Krämer, L., Lausted, C., Eggersdorfer, M., et al. (2017). Optimal nutrition and the ever-changing dietary landscape: a conference report. Eur. J. Nutr. 56, 1-21. doi:10.1007/s00394-017-1460-9

Sharifi-Rad, J., Sharifi-Rad, M., Salehi, B., Iriti, M., Roointan, A., Mnayer, D., et al. (2018). In vitro and in vivo assessment of free radical scavenging and antioxidant activities of Veronica persica poir. Cell. Mol. Biol. 64, 57-64. doi:10.14715/cmb/2018.64.8.9

Shariq, B., Zulhabri, O., Hamid, K., Sundus, B., Mehwish, H., Sakina, R., et al. (2015). Evaluation of anti-atherosclerotic activity of virgin coconut oil in male wistar rats against high lipid and high carbohydrate diet induced atherosclerosis. UK Journal of Pharmaceutical and Biosciences 3, 10-14. doi:10.20510/ukjpb/3/i2/89339
Shortt, C. (2015). "Authorised EU health claims for phytosterols," in Foods, nutrients and food ingredients with authorised EU health claims, Amsterdam: Elsevier, Vol. 2, 31-47.

Strandberg, T. E., Tilvis, R. S., and Miettinen, T. A. (1989). Effects of cholestyramine and squalene feeding on hepatic and serum plant sterols in the rat. Lipids 24, 705-708. doi:10.1007/BF02535208

Sudhop, T., Gottwald, B. M., and Von Bergmann, K. (2002). Serum plant sterols as a potential risk factor for coronary heart disease. Metab. Clin. Exp. 51, 1519-1521. doi:10.1053/meta.2002.36298

Sugano, M., Morioka, H., Kida, Y., and Ikeda, I. (1978). The distribution of dietary plant sterols in serum lipoproteins and liver subcellular fractions of rats. Lipids 13, 427-432. doi:10.1007/BF02533713

Suzuki, K., Tanaka, M., Konno, R., and Kaneko, Y. (2002). Effects of 5campestenone (24-methylcholest-5-en-3-one) on the type 2 diabetes mellitus model animal C57BL/KsJ-db/db mice. Horm. Metab. Res. 34, 121-126. doi:10. $1055 / \mathrm{s}-2002-23194$

Tuomilehto, J., Tikkanen, M. J., Högström, P., Keinänen-Kiukaanniemi, S., Piironen, V., Toivo, J., et al. (2009). Safety assessment of common foods enriched with natural nonesterified plant sterols. Eur. J. Clin. Nutr. 63, 684-691. doi:10.1038/ejcn.2008.11

Vaghini, S., Cilla, A., Garcia-Llatas, G., and Lagarda, M. J. (2016). Bioaccessibility study of plant sterol-enriched fermented milks. Food Funct 7, 110-117. doi:10. 1039/c5fo00458f

Vahouny, G. V., Connor, W. E., Subramaniam, S., Lin, D. S., and Gallo, L. L. (1983). Comparative lymphatic absorption of sitosterol, stigmasterol, and fucosterol and differential inhibition of cholesterol absorption. Am. J. Clin. Nutr. 37, 805-809. doi:10.1093/ajcn/37.5.805

Van Rensburg, S. J., Daniels, W. M., Van Zyl, J. M., and Taljaard, J. J. (2000). A comparative study of the effects of cholesterol, beta-sitosterol, beta-sitosterol glucoside, dehydroepiandrosterone sulphate and melatonin on in vitro lipid peroxidation. Metab. Brain Dis. 15, 257-265. doi:10.1023/a:1011167023695

Vilahur, G., Ben-Aicha, S., Diaz-Riera, E., Badimon, L., and Padró, T. (2019). Phytosterols and inflammation. Curr. Med. Chem. 26, 6724-6734. doi:10.2174/ 0929867325666180622151438

Wadikar, D. D., Lakshmi, I., and Patki, P. E. (2017). Phytosterols: an appraisal of present scenario. Acta Scientific Nutritional Health 1 (1), 25-34.

Weingärtner, O., Bogeski, I., Kummerow, C., Schirmer, S. H., Husche, C., Vanmierlo, T., et al. (2017). Plant sterol ester diet supplementation increases serum plant sterols and markers of cholesterol synthesis, but has no effect on total cholesterol levels. J. Steroid Biochem. Mol. Biol. 169, 219-225. doi:10.1016/j.jsbmb.2016.07.016

Weingärtner, O., Lütjohann, D., Ji, S., Weisshoff, N., List, F., Sudhop, T., et al. (2008). Vascular effects of diet supplementation with plant sterols. J. Am. Coll. Cardiol. 51, 1553-1561. doi:10.1016/j.jacc.2007.09.074

Windler, E., Zyriax, B. C., Kuipers, F., Linseisen, J., and Boeing, H. (2009). Association of plasma phytosterol concentrations with incident coronary heart disease Data from the CORA study, a case-control study of coronary artery disease in women. Atherosclerosis 203, 284-290. doi:10.1016/j. atherosclerosis.2008.06.014

$\mathrm{Xu}, \mathrm{Z}$., Le, K., and Moghadasian, M. H. (2008). Long-term phytosterol treatment alters gene expression in the liver of apo E-deficient mice. J. Nutr. Biochem. 19, 545-554. doi:10.1016/j.jnutbio.2007.06.012

Zakłos-Szyda, M. (2015). Phytosterols in type 2 diabetes and obesity - molecular mechanisms of action. Research Signpost.

Conflict of Interest: The authors declare that the research was conducted in the absence of any commercial or financial relationships that could be construed as a potential conflict of interest.

Copyright (c) 2021 Salehi, Quispe, Sharifi-Rad, Cruz-Martins, Nigam, Mishra, Konovalov, Orobinskaya, Abu-Reidah, Zam, Sharopov, Venneri, Capasso, Kukula-Koch, Wawruszak and Koch. This is an open-access article distributed under the terms of the Creative Commons Attribution License (CC BY). The use, distribution or reproduction in other forums is permitted, provided the original author(s) and the copyright owner(s) are credited and that the original publication in this journal is cited, in accordance with accepted academic practice. No use, distribution or reproduction is permitted which does not comply with these terms. 